1

2

3

4

5

6

7

8

9

10

11

12

13

14

15

16

17

\title{
COMPETITION OF SALTS WITH SULFAMETHOXAZOLE IN AN ANIONIC
} ION EXCHANGE PROCESS

\author{
Ana María López Fernández, PhD, Post-doc. Researcher; \\ Department of Chemical Engineering and Environmental Technology, University of Oviedo, \\ Faculty of Chemistry, C/ Julián Clavería s/n, 33071 Oviedo, Spain. \\ E.mail: ana_If_84@hotmail.com
}

\author{
Manuel Rendueles, Lecturer \\ Department of Chemical Engineering and Environmental Technology, University of Oviedo, \\ Faculty of Chemistry, C/ Julián Clavería s/n, 33071 Oviedo, Spain. E-mail mrenduel@uniovi.es \\ *Corresponding author. Tel.: +34 98 5103439; fax: +34 985106226 \\ Mario Díaz ${ }_{s}$ Prof. \\ Department of Chemical Engineering and Environmental Technology, University of Oviedo, \\ Faculty of Chemistry, C/ Julián Clavería s/n, 33071 Oviedo, Spain. \\ E-mail address: mariodiaz@uniovi.es
}




\section{Abstract}

Sulfamethoxazole is an emergent contaminant in waters. It is an antibiotic for humans and animals that is difficult to biodegrade in drinking water and sewage treatment plants. As the most frequent sulfonamide, its treatment and removal is difficult. In its anionic form, it can be retained by ion exchange, although competition with other ions, especially salts present in natural and treated water, needs to be taken into consideration due to competition between the anions for the active sites of the resin. This work investigated the removal of sulfamethoxazole (SMX) from low saline waters. An anionic ion exchange resin, Lewatit MP500, was used to remove SMX in synthetic solutions in the presence of chloride, sulfate and nitrate salts. Multicomponent system solutions containing a fixed concentration of salts and different concentrations of SMX were tested in batch experiments. The presence of $\mathrm{Cl}^{-}, \mathrm{SO}_{4}{ }^{2-}$ and $\mathrm{NO}_{3}{ }^{-}$suppressed the adsorption of SMX, specially the presence of $\mathrm{SO}_{4}{ }^{2-}$ who showed the highest adsorption capacity onto the resin. Adsorption equilibrium constants were determined using Langmuir isotherm and the Extended Langmuir isotherm for multicomponent systems. The maximum adsorption capacity for the SMX/salts system was $105 \mathrm{mg} / \mathrm{mL}$ wet resin and the equilibrium constants $1.4 \mathrm{~L} / \mathrm{g} \mathrm{SMX}, 6 \mathrm{~L} / \mathrm{g} \mathrm{NO}_{3}{ }^{-}, 9 \mathrm{~L} / \mathrm{g} \mathrm{SO}_{4}{ }^{2-}$. Kinetics was analyzed using the pore diffusion model, getting a diffusivity value of $1.3 \cdot 10 \mathrm{~cm}^{2} / \mathrm{s}$ for SMX. Finally, two operational load and elution cycles were carried out in a fixed bed column using mixture synthetic solutions of SMX and salts to obtain the corresponding breakthrough curves. Results show that the resin is able to retain SMX despite the high competition of the other anions and can be regenerated completely after each cycle.

Keywords: ion exchange, pharmaceutical contaminants, isotherms, kinetics, fixed bed operation 


\section{Introduction}

The presence of antibiotics in the ecosystem has been known for almost 30 years.

45

46

47

In recent years, the use of antibiotics in veterinary and human medicine has become widespread, with the ensuing increase in water contamination by these compounds. Human and veterinary antibiotics are detected in different matrices. These contaminants are continually discharged into the natural environment by a diversity of input sources (households, industries, hospitals, aquaculture, livestock, poultry and pets). Most wastewater treatment plants (WWTPs) are not designed to remove highly polar micro pollutants like antibiotics (Xu et al. 2007; Díaz-Cruz et al. 2003). Therefore, they may be transported to surface waters and reach groundwater after leaching. Ultimately, contaminated surface waters can enter into drinking water treatment plants (DWTPs), which are likewise not equipped to remove these compounds, which eventually reach the water distribution system. Practical, economical solutions must therefore be developed to reduce the daily amounts of antibiotics discharged into the environment.

A wide range of chemical and physical methodologies can be employed for the removal of organic compounds. Different methods may be chosen depending on the concentration of the pollutant in the effluent and the cost of the process (Homen and Santos 2011). The treatment options typically considered for the removal of emerging contaminants include activated sludge systems (Carballo et al. 2013), adsorption (Grassi et al. 2012), Advanced Oxidation Processes (AOPs) (Andreozzi et al. 2005; Balcioğlu et al. 2003; Trovó et al. 2009; Pérez-Moya et al. 2010), Nanofiltration (NF), and Reverse Osmosis (RO) membranes ( $\mathrm{Li}$ et al. 2004). Although processes such as advanced oxidation can convert antibiotic molecules into compounds or even mineralize them completely, these processes are very expensive (Mehrjouei et al. 2014) and difficult to 
maintain for the total removal of compounds including antibiotics at industrial scale. Besides, these processes can lead to the formation of oxidation intermediates that are as yet mostly unknown (Grassi, 2012). On the other hand, physicochemical treatments such as coagulation/flocculation processes (Vieno et al. 2007; Stackelberg et al. 2007) have generally been found to be unable to remove Endocrine Disrupting Compounds and Personal Care Products.

Adsorption processes do not add undesirable by-products and have been found to be better than other techniques for wastewater in terms of simplicity of design and operation, and insensitivity of toxic substances (Tong et al. 2010; Ahmed et al. 2015). Among several materials used as adsorbents, Activated Carbons (ACs) have been used to remove different types of emerging compounds in general, although their use is sometimes restricted due to their high cost (Putra et al. 2009; Rivera-Utrilla et al. 2009). Moreover, when AC has been exhausted, it can be regenerated for further use, although the regeneration process results in a loss of carbon, and the regenerated product may have a slightly lower adsorption capacity compared to the virgin activated carbon. Many researchers also have investigated the adsorptive removal of pharmaceuticals by carbon nanotubes (Ji et al. 2010; Cho et al. 2011), soils (Sukul et al. 2008), natural aquifer materials (Hari et al. 2005) and sediments (Stein et al. 2008). However, these natural adsorbents have a number of drawbacks in terms of availability, effectiveness and regeneration problems. Therefore, interest in alternative adsorbents has subsequently grown with the aim of finding new low-cost adsorbents (Gupta et al. 2009; Crisafully et al. 2008).

Polymeric resins are becoming more common in wastewater treatment due to their low cost, easy regeneration and selective removal of pollutants. Adams et al. (2002) and Choi et al. (2007) studied the use of polymeric resin for the removal of sulfonamides and 
tetracyclines. They obtained high removal efficiencies ( $90 \%$ for sulfonamides and $>80 \%$ for tetracyclines). Vergili and Barlas (2009) studied the adsorption of carbamazepine, propyphenazone and sulfamethoxazole using a polymeric resin, Lewatit VP OC 1163. This resin showed a large adsorption capacity for pharmaceuticals with low solubility. Most recently, Jiang et al. (2015) studied the removal of pharmaceuticals like sulfadiazine by two magnetic ion exchange resins and the effect of the co-existing anions, chloride and sulfate, on the adsorption process. However, the information of pharmaceuticals removal by porous resins remains limited, although porous resins are one of the most effective adsorbents for purifying waters.

Sulfamethoxazole (SMX) is a common antibacterial antibiotic sulfonamide that is widely used to treat urinary tract infections in humans and animals. It prevents the formation of dihydrofolic acid, a compound that bacteria must be able to produce in order to survive. It is also the most frequently detected sulfonamide in municipal sewage. It is not biodegradable and its persistence in the environment is larger than one year.

The aim of this work was to determine the feasibility of ion exchange treatment of low saline natural waters contaminated with sulfamethoxazole (SMX) in the presence of chloride, nitrate and sulfate salts. A macroporous strong anionic resin was tested in batch and packed-column experiments using aqueous solutions of SMX with salts, to determine its capacity to retain SMX in the presence of these salts, the effect of the coexisting anions, and comparing the results with those previously obtained for SMX in single solutions. In this case, the ion exchange resin used has been Lewatit MP500, as example of commercial strong anionic sorbents. Equilibrium and kinetics were studied in batch in order to characterize the operation. Several load and elution cycles were performed in a fixed bed column to evaluate the behavior of the resin in an industrial 
operation. Breakthrough curves of load and elution were fitted using a fixed-bed adsorption model.

\section{Materials and methods}

\section{Reagents and Adsorbent}

Among sulfonamides, sulfamethoxazole (SMX) was selected in this study because is one of the most commonly used. Sulfamethoxazole (purity>98\% w/w), was purchased from Sigma-Aldrich. The physicochemical properties of SMX are: Molecular weight $253.28, \mathrm{pKa}=1.6 / 5.7, \log \mathrm{K}_{\mathrm{ow}}=0.89$.

Inorganic salts $\mathrm{K}_{2} \mathrm{SO}_{4}$ (purity $\geq 99 \% \mathrm{w} / \mathrm{w}$ ), $\mathrm{NaNO}_{3}$ (purity $\geq 99 \% \mathrm{w} / \mathrm{w}$ ) and $\mathrm{NaCl}$ (purity $\geq 99 \% \mathrm{w} / \mathrm{w}$ ), used as co-existing anions, were purchased from Sigma-Aldrich.

The aqueous solutions of SMX and salts were prepared at concentrations between 62-124 mg/L SMX and a fixed concentration of salts $\left(250 \mathrm{mg} / \mathrm{L} \mathrm{SO}_{4}{ }^{2-}, 250 \mathrm{mg} / \mathrm{L} \mathrm{Cl}^{-}\right.$and $\left.50 \mathrm{mg} / \mathrm{L} \mathrm{NO}_{3}{ }^{-}\right)$. In the case of individual experiments of nitrate, sulfate and chloride salts, the solutions were prepared at concentrations of between $50-125 \mathrm{mg} / \mathrm{L}$ for $\mathrm{NO}_{3}{ }^{-}, 50-300$ $\mathrm{mg} / \mathrm{L}$ for $\mathrm{SO}_{4}{ }^{2-}$ and $50-350 \mathrm{mg} / \mathrm{L}$ for $\mathrm{Cl}^{-}$.

Methanol (HPLC (High Pressure Liquid Chromatography) grade) used for liquid chromatography was purchased from Sigma-Aldrich, and ultra-pure water was prepared in a Milli-Q purification system. The filters used for filtration were obtained from Millipore (0.45 $\mu \mathrm{m}$ pore PVDF (polyvinylidene difluoride) for samples) and Whatman (0.22 $\mu \mathrm{m}$ pore PTFE (Polytetrafluoroethylene) for the mobile phase). Experiments were carried out at $\mathrm{pH}$ values of aqueous solutions of between 5.0 and 5.5.

A commercial organic polymeric resin (Lewatit MP500) manufactured by Lanxess was used as adsorbent. The strong base resin Lewatit MP500 has a quaternary 
amine (macroporous type I) and a crosslinked polystyrene matrix. The main properties of the resin are shown in Table 1.

\section{Table 1}

\section{Analytical methods}

Determination of sulfamethoxazole in the samples was performed using HPLC (Agilent 1200) combined with UV detection, using a reverse-phase column from Teknokroma (Mediterranea Sea18, $5 \mu \mathrm{m}$ x $25 \mathrm{~cm}$ x $46 \mathrm{~cm}$ ). Prior to HPLC analysis, the samples were treated using $0.45 \mu \mathrm{m}$ PVDF filters to ensure that they were free of other compounds that might interfere in the analysis. The mobile phase consisted of eluent $\mathrm{A}$ (methanol) and eluent B (water). The method was isocratic (60\% of eluent A and $40 \%$ of eluent B). Analysis was performed at a flow rate of $0.7 \mathrm{~mL} / \mathrm{min}$. The wavelength used for detection was $270 \mathrm{~nm}$ and the retention time was 4.9 min. The column compartment temperature was $40^{\circ} \mathrm{C}$. Injection volume: $20 \mu \mathrm{L}$.

The determination of salts (chloride, nitrate and sulfate) was performed using an Ion Chromatograph (DIONEX 120). The mobile phase was a mixture of $\mathrm{Na}_{2} \mathrm{CO}_{3}$ and $\mathrm{NaHCO}_{3}\left(4.5 \mathrm{mM} \mathrm{CO}_{3}{ }^{2-}\right.$ and $\left.0.8 \mathrm{mM} \mathrm{HCO}_{3}{ }^{-}\right)$. The retention times were $2.58 \mathrm{~min}$ for $\mathrm{Cl}^{-}$, $4.33 \mathrm{~min}$ for $\mathrm{NO}_{3}{ }^{-}$and $10.33 \mathrm{~min}$ for $\mathrm{SO}_{4}{ }^{2-}$.

\section{Experimental Method}

\section{Batch Experiments}

Runs were carried out at room temperature in cylindrical stirred tanks of $500 \mathrm{~mL}$, operating in a magnetic stirring at a speed of $300 \mathrm{rpm}$. This agitation rate would be sufficient to eliminate the film mass transfer resistance in the ion exchange process, 
162 because film diffusion control may prevail in systems with dilute solutions and with inefficient agitation (Helfferich 1962), which is not the case. Furthermore, at this agitation rate it was tested that the particles did not break, maintaining their integrity along the experiments. Initially, as the ionic form of the wet resin was $\mathrm{Cl}^{-}$, the conditioning was carried out by contacting the resin with a solution of $\mathrm{NaOH} 1 \mathrm{M}$ with an $\mathrm{L} / \mathrm{S}$ ratio (volume of liquid $(\mathrm{mL}) /$ mass of wet resin $(\mathrm{g}))=20,2$ times, 20 minutes each time, to exchange the $\mathrm{Cl}^{-}$groups by $\mathrm{OH}^{-}$groups. The resin was then washed with distilled water twice for 5 minutes each time with an L/S ratio $=50$ and subsequently separated from the solution. The resin was then contacted with the loading solution containing $250 \mathrm{mg} / \mathrm{L} \mathrm{SO}_{4}{ }^{2-}$ 
from the tank each time was $2 \mathrm{~mL}$, which did not substantially change the volume of the solution. The concentration of SMX, chloride, sulfate and nitrate ions in the resin were determined by mass balance, calculating the difference between the initial and final amount of charged ions in the solution.

\section{Column Experiments}

Continuous flow adsorption experiments were carried out in a glass column with an internal diameter of $1.1 \mathrm{~cm}$ and a total tube length of $25 \mathrm{~cm}$. Column was prepared by packing with 2 grams $(1.9 \mathrm{~mL})$ of wet resin. Solutions were pumped through the column by a peristaltic pump (Masterflex7554-60 pump) using down-flow mode in both loading and elution steps. Previous work with sulfamethoxazole using up-flow in the elution step showed the same results than using down-flow mode. It was independent of the direction of the flow which means, it did not create preference channels along the fixed bed in the column. Therefore, we assumed that flow direction is independent in the adsorption process, selecting down-flow mode in this case.

The packed column was activated by pumping through a $1 \mathrm{M} \mathrm{NaOH}$ solution for 20 minutes, at a flow rate of $11 \mathrm{~mL} / \mathrm{min}$. Then, distilled water was fed through the column at a flow rate of $11 \mathrm{~mL} / \mathrm{min}$ for 15 minutes to wash the resin.

Two load stages using synthetic solutions containing $125 \mathrm{mg} / \mathrm{L} \mathrm{SMX,} 250 \mathrm{mg} / \mathrm{L}$ $\mathrm{Cl}^{-}, 250 \mathrm{mg} / \mathrm{L} \mathrm{SO}_{4}{ }^{2-}$ and $50 \mathrm{mg} / \mathrm{L} \mathrm{NO}_{3}{ }^{-}$in the first stage, and $90 \mathrm{mg} / \mathrm{L} \mathrm{SMX}$ and the same concentration of salts in the second stage were carried out at a down-flow rate of 11 $\mathrm{mL} / \mathrm{min}$ and $10.5 \mathrm{~mL} / \mathrm{min}$, respectively. Effluent samples (4 $\mathrm{mL}$ approximately) were collected at specified times intervals (5-10 minutes) and measured by HPLC and IC to monitor the evolution of SMX and salt concentrations over time. The breakthrough curve was plotted until the concentration at the outlet of the column effluent reached the initial 
concentration of the feed solution. After adsorption, distilled water was fed through the column to remove any unabsorbed ions on the adsorbent surface or entrapped between adsorbent particles.

After each loading, an elution step was carried out by pumping a $0.5 \mathrm{M} \mathrm{NaOH}$ solution through the column at a down-flow-rate of $10 \mathrm{~mL} / \mathrm{min}$ and $9 \mathrm{~mL} / \mathrm{min}$, respectively. Effluent samples were collected at the outlet of the column every 5-10 minutes to monitor the evolution of the concentration over time. The elution curve was plotted until no concentrations were detected at the column outlet.

\section{$218 \quad$ Results and discussion}

219

220

\section{Batch equilibrium study}

In order to evaluate the capacity of the MP500 resin to retain SMX in presence of salts, several runs were carried out using different L/S ratios (volume of liquid (mL)/mass of wet resin $(\mathrm{g}))=150,200$ and 250, using synthetic solutions of SMX and a fixed concentration of salts (chloride, sulfate and nitrate) in each experiment. The solutions were prepared using $250 \mathrm{mg} / \mathrm{L} \mathrm{Cl}^{-}, 250 \mathrm{~g} / \mathrm{L} \mathrm{SO}_{4}{ }^{2-}, 50 \mathrm{mg} / \mathrm{L} \mathrm{NO}_{3}{ }^{-}$, and different concentrations of SMX (between 62 and $124 \mathrm{mg} / \mathrm{L} \mathrm{SMX).} \mathrm{The} \mathrm{concentrations} \mathrm{of} \mathrm{each}$ compound were monitored over time until reaching equilibrium. Equilibrium concentrations were obtained within 100 minutes. A mass balance was used to determine the equilibrium compositions of each anion in the resin and in the solution phase. The equilibrium concentrations obtained and their respective adsorption capacities are shown in Table 2. In the case of chloride, the retention capacity was very low. The resin showed more affinity for the other compounds that is consistent with the results obtained in individual systems, where chloride exhibited lower adsorption capacity than the other compounds. 
Table 2

234

235

236

237

238

239

240

241

242

243

244

245

246

247

248

249

250

251

252

The Langmuir adsorption isotherm is the best known and the most widely used isotherm for modelling the adsorption of a solute from a liquid solution. Therefore, it was used to define the relationship between the resin load capacity and the equilibrium solution concentration of salts in single systems and in mixtures of SMX together with salts, without considering the presence of the salts in solution. The adsorption capacity obtained was compared with the previous value obtained in SMX single system. The Langmuir equation is described as:

$$
q_{e, i}=\frac{K_{e q} \cdot q_{T} \cdot C_{e, i}}{1+K_{e q} \cdot C_{e, i}}
$$

where $\mathrm{K}_{\mathrm{eq}}$ is the equilibrium constant $(\mathrm{L} / \mathrm{g}), \mathrm{q}_{\mathrm{T}}$ is the maximum adsorption capacity of the resin $\left(\mathrm{g} / \mathrm{L}\right.$ resin), $\mathrm{C}_{\mathrm{e}, \mathrm{i}}$ is the equilibrium solution concentration of species $\mathrm{i}(\mathrm{g} / \mathrm{L})$, and $\mathrm{q}_{e, \mathrm{i}}$ is the amount of specie $\mathrm{i}$ adsorbed by the resin at equilibrium ( $\mathrm{g} / \mathrm{L}$ resin). The equilibrium constant and the maximum absorption capacity were obtained using the Statgraphic program. Fig. 1 and Fig. 2 compare the experimental results with the values predicted by the Langmuir isotherm for SMX in mixtures considering no competition between each substance, and for each salt individually, respectively.

\section{Fig. 1}

\section{Fig. 2}



experimental results and predicted values by the model. The different isotherm parameters obtained for SMX in mixtures using the Langmuir isotherm were: $\mathrm{K}_{\text {eq-Lang }}=$ 11.8 L/g and $\mathrm{q}_{\mathrm{T}-\mathrm{Lang}}=17.2 \mathrm{~g} \mathrm{SMX/L}$ wet resin, with a correlation coefficient $\mathrm{R}^{2}=0.994$. Comparison of these results with those obtained in a previous study on SMX in a single system (Fernández et al. 2013, Lopez, 2014) allows the determination of the loss in capacity of the resin to remove SMX due to the presence of salts in the aqueous solution. The parameters obtained for $\mathrm{SMX}, \mathrm{NO}_{3}{ }^{-}, \mathrm{SO}_{4}{ }^{2-}$ and $\mathrm{Cl}^{-}$in single component systems are summarized in Table 3. data observations, an objective function relating the experimental and the predicted

\section{Table 3} component uptake may be defined as (Shallcross et al. 1988):

$$
E_{i}=\sum_{j=1}^{Q}\left(\frac{q_{i}^{\text {exp }}-q_{i}^{\text {model }}}{q_{i}^{\text {exp }}}\right)^{2}
$$

where $Q$ is the number of data points: $\mathrm{j}=1 \ldots \mathrm{Q}$, and $q_{i}^{\text {exp }}$ and $q_{i}^{\text {model }}$ are the experimental and the predicted adsorption capacities. The error function value $\left(E_{\mathrm{i}}\right)$ obtained for each salt in single component system is presented in Table 3. mixtures, it can be seen that the maximum adsorption capacity for SMX decreases considerably from $258 \mathrm{~g} \mathrm{SMX/L}$ wet resin to $17.2 \mathrm{~g} \mathrm{SMX/L} \mathrm{wet} \mathrm{resin} \mathrm{in} \mathrm{mixtures,} \mathrm{which}$ means a loss of adsorption capacity of $93 \%$. Therefore, the existence of anions in the solution impedes the exchange of the adsorbate with the resin. Moreover, the addition of 
chloride, sulfate and nitrate salts to the solution may influence the diffusion of sulfamethoxazole in the water and the interactions between SMX and Lewatit MP500. A reduction in the capacity to adsorb SMX means that the presence of salts in the solution interferes in the adsorption process. This is in concordance with the results obtained from Jiang et al. (2015) who found that the adsorption capacity of another sulfamide, sulfadiazine (SDZ), decreases in presence of chloride and sulfate in more than $80 \%$. Hence, competitive adsorption using the Extended Multicomponent Langmuir isotherm, Eq. (3), was used to model the experimental data.

$$
q_{e, i}=\frac{K_{e q, i} \cdot q_{T} \cdot C_{e, i}}{1+\sum_{j} K_{e q, j} \cdot C_{e, j}}
$$

where $q_{e, i}$ is the amount of solutes adsorbed per unit of adsorbent at equilibrium concentrations, $C_{e, i}(\mathrm{~g} / \mathrm{L}), \mathrm{q}_{\mathrm{T}}$ is the maximum uptake capacity $(\mathrm{g} / \mathrm{L}$ resin) for the system (SMX and salts), and $K_{e q, i}(\mathrm{~L} / \mathrm{g})$ is the equilibrium constant of each solute. This Langmuir equation is a simple extension of the single-component Langmuir isotherm to account for multicomponent adsorption. This model assumes: i) a homogeneous surface with respect to the energy of adsorption, and ii) all adsorption sites are equally available to all adsorbed species.

Note that the model actually consist of three equations, one to compute the uptake of the first component and other two for the uptakes of the other two compounds, respectively. Worth noting that the chloride has not been taken into account because of the low adsorption capacities got, almost zero. Therefore, the model comprises four parameters (Chong and Volesky 1995): $q_{T}, K_{e q ~ S M X}, K_{e q ~ N O 3^{-}}$and $K_{e q ~ S O 4^{2-}}$. The computer program Scientific was used to evaluate these parameters. The values obtained were: $K_{e q}$ $S M X=1.4 \mathrm{~L} / \mathrm{g} \mathrm{SMX}, K_{e q N O 3^{-}}=6 \mathrm{~L} / \mathrm{g} \mathrm{NO}_{3}{ }^{-}, K_{e q} S O 4^{2^{-}}=9 \mathrm{~L} / \mathrm{g} \mathrm{SO}_{4}{ }^{2-}$ and $q_{T}=105 \mathrm{~g} / \mathrm{L}$ wet resin for the $\mathrm{SMX} / \mathrm{NO}_{3}{ }^{-} / \mathrm{SO}_{4}{ }^{2-}$ system, with a correlation coefficient $\mathrm{R}^{2}=0.999$. Comparison 
between experimental data and the values predicted by the extended Langmuir equation for a multicomponent system of SMX with salts is shown in Table 2. The experimental data and predicted values obtained for this system are given in Fig. 3. The effect of sulfate, nitrate and chloride on pharmaceutical removal differed, with $\mathrm{SO}_{4}{ }^{2-}>\mathrm{NO}_{3}{ }^{-}>\mathrm{Cl}^{-}$. This result can be attributed to the different affinities between anions and the adsorption sites on the resin. Therefore, the higher value of the $K_{\text {eq,i } i}$ parameter for $\mathrm{SO}_{4}{ }^{2-}$ than for $\mathrm{NO}_{3}{ }^{-}$and SMX implies that Lewatit MP500 has a higher affinity for $\mathrm{SO}_{4}{ }^{2-}$ than for $\mathrm{NO}_{3}{ }^{-}$or $\mathrm{SMX}$. 307

Batch kinetics study

Kinetics experiments were carried out in batch mode with mixtures of SMX and

salts in a multicomponent system monitoring SMX, nitrate, sulfate and chloride concentrations over time from the initial time to equilibrium time for all solutions, and also with each salt in single component system.

\section{Multicomponent system} substantially after 100 minutes, so operational equilibrium may be assumed. The experiments were conducted in a stirred tank using synthetic solutions with initial assuming an adsorption process, seeing as the rate controlling step in ion exchange is usually the diffusion of the counter anions rather than the chemical exchange reaction at the fixed ions groups. This means that the ion-exchange operation is essentially a 
diffusion phenomenon. Under the operating conditions used such as high stirred speed of $300 \mathrm{rpm}$, the rate controlling step is expected to be the intraparticle diffusion (Helfferich 1962). Therefore, the concentration profiles of SMX in mixtures can be modeled using the pore diffusion kinetics model:

Pore Diffusion Model. This model considers the resin to be a porous matrix (Rodrigues and Tondeur 1981; Costa and Rodrigues 1985b). The model is described by the following equations:

- Mass balance inside the particle:

$$
\frac{\partial q(R, t)}{\partial t}+\varepsilon_{i} \frac{\partial C_{p}(R, t)}{\partial t}=\frac{1}{R^{2}} \frac{\partial}{\partial R}\left[R^{2} \varepsilon_{i} D_{p} \frac{\partial C_{p}(R, t)}{\partial R}\right]
$$

where $q$ is the solute concentration within the resin matrix due to the interaction with the fixed charge, $C_{p}$ is the concentration of solute in the particle pores, $\varepsilon_{i}$ is the particle porosity, $D_{p}$ is the pore diffusivity and $R$ is the radial coordinate.

- Mass balance in the bulk solution:

$$
\varepsilon_{l} V\left(C_{0}-C(t)\right)=\left(1-\varepsilon_{l}\right) V\left(\overline{q+\varepsilon_{l} C_{p}}\right)
$$

where $C_{0}$ is the initial concentration of species $i$ in solution, $V$ is the volume of solution and $\varepsilon_{l}$ is the adsorbent porosity.

- Average concentration in the particle:

$$
\overline{q+\varepsilon_{l} C_{p}}=\frac{3}{R_{0}^{3}} \int_{0}^{R_{0}} R^{2}\left(q(R, t)+\varepsilon_{i} C_{p}(R, t)\right) d R
$$

where $\mathrm{R}$ is the radial coordinate and $\mathrm{R}_{0}$ is the particle radius.

- Interphase pore at equilibrium

$$
q(R, t)=f\left(C_{p}(R, t)\right)
$$


$q$ and $C_{p}$ was correlated using the equilibrium isotherm described previously.

- Initial conditions:

$$
\text { At the interphase }\left(\mathrm{R}=\mathrm{R}_{0}\right) \rightarrow C_{p}\left(R_{0}, t\right)=C(t)
$$

Fig. 4 shows the fit of the experimental results to this model for all the assays. The good agreement between experimental data and the theoretical prediction shows the goodness of the model. Comparing the value obtained in these assays with the value obtained in single assays of SMX, $D_{p}$ SMX alone $=2.6 \cdot 10^{-10} \mathrm{~cm}^{2} / \mathrm{s}$ (Fernández et al. 2013, Lopez, 2014), the diffusivity value for SMX in mixtures are higher. 


\section{Fig.4}

The chloride, nitrate and sulfate adsorption processes were monitored from the initial time to equilibrium time for all solutions. The ion exchange operation was taken from the loading experiments conducted in stirred tanks with synthetic solutions of chloride, sulfate and nitrate salts. In the case of SMX, the results have been reported in a previous paper (Fernández et al. 2013). The concentration profiles of chloride, sulfate and nitrate salts can be studied using pore diffusion kinetics model as described above in section Multicomponent system. $\mathrm{cm}^{2} / \mathrm{s}, D_{p \text {-sulfate }}=2.7 \cdot 10^{-8} \mathrm{~cm}^{2} / \mathrm{s}$ and $D_{\text {p-nitrate }}=2.3 \cdot 10^{-8} \mathrm{~cm}^{2} / \mathrm{s}$. The average percentage error values obtained from Eq.(12) were: $\varepsilon(\%)=3.3-5.3$ for nitrate, $\varepsilon(\%)=1.3-6.8$ for sulfate, and $\varepsilon(\%)=0.6-1.9$ for chloride. Fig. 5 shows a comparison of experimental data and the values predicted by the pore diffusion model for each component, obtaining a good correlation between both sets of values.

\section{Fixed Bed Operation}

Breakthrough Curves for the Load and Elution Steps. After studying the 
a fixed concentration of salts of $250 \mathrm{mg} / \mathrm{L} \mathrm{Cl}^{-}, 250 \mathrm{mg} / \mathrm{L} \mathrm{SO}_{4}{ }^{2-}$ and $50 \mathrm{mg} / \mathrm{L} \mathrm{NO}_{3}{ }^{-}$, to obtain the corresponding breakthrough curves.

Operation in a fixed bed column was initially tested using a synthetic solution of $125 \mathrm{mg} / \mathrm{L} \mathrm{SMX}$ and salts in the aforementioned concentrations, a volume of resin of 1.9 $\mathrm{mL}$ and a flow rate of $11 \mathrm{~mL} / \mathrm{min}$ for 180 minutes. The amount of resin and the flow rate in load and elution steps was the same as those used in previous assays using SMX alone that was found to be adequate to achieve saturation of the resin.

The breakthrough curves for the load step show scattered results for all compounds, with no pronounced jump in concentration being observed over time. The breakthrough point, in which $\mathrm{C} / \mathrm{C}_{0}>0.1$, was considered from the initial time because concentrations of all compounds over $10 \%$ the initial concentration were detected from the first minutes of operation onwards. Equilibrium subsequently being achieved for all anions in 60 minutes. SMX reached its equilibrium concentration in 5 minutes and $\mathrm{Cl}^{-}$in 30 minutes, while $\mathrm{NO}_{3}{ }^{-}$and $\mathrm{SO}_{4}{ }^{2-}$ did so in 60 minutes. The retention capacity of the resin packed in the column was calculated by numerical integration of the area below the breakthrough curves of the load step. The operational capacity of the bed was found to be: $5 \mathrm{mg} \mathrm{SMX} / \mathrm{mL}$ wet resin, $15 \mathrm{mg} \mathrm{NO}_{3}{ }^{-} / \mathrm{mL}_{\text {wet }}$ resin, $42 \mathrm{mg} \mathrm{Cl}^{-} / \mathrm{mL}$ wet resin and 50 $\mathrm{mg} \mathrm{SO}_{4}{ }^{2-} / \mathrm{mL}$ wet resin.

Resin life is one of the key parameters for determining the kind of resin to be applied in industrial production. After adsorption, the resin was regenerated with a $0.5 \mathrm{M}$ $\mathrm{NaOH}$ solution at a flow rate of $10 \mathrm{~mL} / \mathrm{min}$ for 60 minutes. The concentration at the outlet of the column was negligible for all compounds within 20 minutes, recovering nearly $100 \%$ of all compounds in the elution step. Sulfate presented a high elution peak in the first minutes of operation, reaching a concentration of $1143 \mathrm{mg} / \mathrm{L}$, approximately 4 times 
411 the initial concentration, which means the initial sample was concentrated. In the case of

412 SMX, nitrate and chloride, a high elution peak was not detected and similar 413 concentrations to their respective initial concentrations were obtained from the first 414 minutes. This agrees with the results obtained in the load step, in which the resin exhibited 415 a higher capacity of adsorption for the sulfate salt than for SMX, nitrate and chloride salts. 416 Therefore, the resin has more capacity to adsorb and concentrate sulfate than the other compounds. The breakthrough curves for the load and elution steps are shown in Fig. 6a418 e.

\section{Fig. 6a-e}

After this first cycle of load and elution in a column setup, another cycle was carried out using a concentration of $90 \mathrm{mg} / \mathrm{L} \mathrm{SMX}$ and salts in concentrations of 250 $\mathrm{mg} / \mathrm{L}$ sulfate, $250 \mathrm{mg} / \mathrm{L}$ chloride and $50 \mathrm{mg} / \mathrm{L}$ nitrate to study the behavior of the resin, operating at a flow rate of $10.5 \mathrm{~mL} / \mathrm{min}$ for 180 minutes. As in the previous cycle, SMX was detected at the outlet of the column from the first minutes of operation onwards. SMX reached the concentration of initial sample in 20 minutes, subsequently remaining constant until the end of the operation. The sulfate salt showed the breakthrough point $\left(\mathrm{C} / \mathrm{C}_{0}>0.1\right)$ at 10 minutes, increasing quickly until saturation of the resin in 70 minutes. In the case of chloride salt, the breakthrough point was at 10 minutes, growing quickly until $340 \mathrm{mg} / \mathrm{L}$ in 20 minutes, hence above its initial concentration in the sample. It then decreased to $250 \mathrm{mg} / \mathrm{L}$, subsequently remaining constant until the end of operation. This means that the chloride front was displaced by the sulfate within the fixed bed and hence a chloride elution peak was observed ahead of the sulfate front (Arévalo et al. 1998). The nitrate salt was detected at the outlet of the column in concentration above $10 \%$ of initial sample concentration after 15 minutes of operation, considering this time as the 
breakthrough point, increasing progressively until nearly reaching its initial concentration in 70 minutes, and subsequently remaining constant until the end of operation. The operational capacity of the bed was found to be: $4 \mathrm{mg} \mathrm{SMX} / \mathrm{mL}$ wet resin, $7 \mathrm{mg} \mathrm{NO}{ }_{3}^{-} / \mathrm{mL}^{-}$ wet resin, $49 \mathrm{mg} \mathrm{Cl}^{-} / \mathrm{mL}$ wet resin and $57 \mathrm{mg} \mathrm{SO}_{4}{ }^{2-} / \mathrm{mL}_{\text {wet }}$ resin. of $9 \mathrm{~mL} / \mathrm{min}$ for 60 minutes. As in the previous cycle, a high elution peak was detected in the case of the sulfate salt, reaching a concentration of $2656 \mathrm{mg} / \mathrm{L}$ ( 9.5 times the initial concentration). It then decreased rapidly, being completely removed in 20 minutes. Nitrate reached a concentration of $115 \mathrm{mg} / \mathrm{L}$ (2.6 times its initial concentration), also being completely removed in 20 minutes; chloride reached a concentration of $436 \mathrm{mg} / \mathrm{L}$ (1.6 times its initial concentration), being totally removed in 60 minutes. In the case of SMX, not high peak was detected in the first minutes of operation seeing as the concentration decreased very quickly, less than $10 \mathrm{mg} \mathrm{SMX/L} \mathrm{being} \mathrm{detected} \mathrm{at} \mathrm{the} \mathrm{outlet}$ from the first minutes of operation, obtaining complete removal in 10 minutes. As in the other cycle, nearly $100 \%$ of all compounds were recovered. The breakthrough curves for the load and elution steps of the second cycle are shown in Fig. 7a-e. despite the presence of the co-existing anions, the adsorption capacity of SMX is similar which means it does not lost adsorption capacity after several uses, and it can be regenerated completely after each cycle. 

SMX in a fixed bed column, a high decrease in the capacity to adsorb SMX can be observed. In single assays employing an initial concentration of $200 \mathrm{mg} \mathrm{SMX/L}$ and a flow rate of $11 \mathrm{ml} / \mathrm{min}$, an adsorption capacity of $194 \mathrm{mg} \mathrm{SMX/mL}$ wet resin (Fernández et al. 2013, Lopez, 2014) was obtained. Now, using $125 \mathrm{mg} \mathrm{SMX/L} \mathrm{in} \mathrm{mixtures,} \mathrm{an}$ adsorption capacity of $5 \mathrm{mg} \mathrm{SMX} / \mathrm{mL}$ wet resin was obtained. This means that the presence of salts in solution affects the resin's capacity to adsorb SMX. The breakthrough curves represent the total retention, so the physical retention of ions in the bed as the ion exchange retention. When the concentration of the ion, for instance $\mathrm{Cl}^{-}$, in the liquid is high, the term of interparticle retention is high, and the total retention capacity is high, even if the ion exchange term is null or nearly null. This interparticle retention is not present in batch experiments where only intraparticle and ion exchange retention takes place. The batch experiments allow to determine the real ion exchange capacity and the fixed bed experiments the total retention capacity. This is very important in this case, where the concentration of the co-ions is very high compared with SMX, and serves to determine that the resin, even in these conditions, presents a good retention capacity for 473 SMX.

\section{$474 \quad$ Fixed Bed Model}

In the cases of the load and elution curves, analysis of the fixed bed experiments was carried out considering a model developed by Costa and Rodrigues (1985a) and 477 applied by Fernández et al. (1994, 1995). This model was used to simulate the load and elution breakthrough curves in a laboratory column. The model takes into account aspects 479 of equilibrium and kinetics, and axial dispersion in the column. The developed model can 480 be seen in Fernández et al. (2013). 

diffusivities in the pores and the capacity of the resin must be known to solve the fixed bed model. Bed porosity and particle porosity was determined in previous work case are:

$$
\begin{aligned}
\frac{1}{P e} \frac{\partial^{2} x_{i}\left(z^{*}, \theta_{s t}\right)}{\partial z^{* 2}} & -\frac{\partial x_{i}\left(z^{*}, \theta_{s t}\right)}{\partial z^{*}} \\
& =\frac{\partial x_{i}\left(z^{*}, \theta_{s t}\right)}{\partial \theta_{s t}}+\frac{15 \varepsilon_{i}\left(1-\varepsilon_{l}\right) N_{D i}}{\varepsilon_{l}}\left[x_{i}\left(z^{*}, \theta_{s t}\right)-\bar{x}_{p l}\left(z^{*}, \theta_{s t}\right)\right]
\end{aligned}
$$

491

493

$$
\frac{\partial x_{p i}\left(z^{*}, \theta_{s t}\right)}{\partial \theta_{s t}}=\frac{15 \varepsilon_{i} N_{D i}}{\varepsilon_{i}+\frac{K_{i} q_{T i} / c_{T i}}{\left(1+\left(K_{i}-1\right) x_{P i}\left(z^{*}, \theta_{s t}\right)\right)^{2}}}\left[x_{i}\left(z^{*}, \theta_{s t}\right)-\overline{x_{p l}}\left(z^{*}, \theta_{s t}\right)\right]
$$

495

Obtained via the relationship:

497

$$
\frac{\partial q_{i}}{\partial t}=\frac{\partial q_{i}}{\partial C_{i}} \frac{\partial C_{i}}{\partial t}
$$




$$
z^{*}=0 \quad x_{i}\left(z^{*}, \theta_{s t}\right)=x_{T i}
$$

$$
z^{*}=L \quad \frac{\partial x_{i}\left(z^{*}, \theta_{s t}\right)}{\partial z^{*}}=0
$$

- Initial conditions:

508

509

$$
\theta_{\mathrm{st}}=0 \quad x_{i}\left(z^{*}, \theta_{s t}\right)=x_{T i} \quad \text { in } \mathrm{z}^{*}=0
$$

510

$$
\theta_{\mathrm{st}}=0 \quad x_{i}\left(z^{*}, \theta_{s t}\right) \text { depends on washing } \forall \mathrm{z}^{*}>0
$$

The space coordinate inside the column $z^{*}$ is normalized by L, the length of the column; time by the stoichiometric time of SMX, $\mathrm{t}_{\mathrm{st}}$, i.e. the time for the resin to become completely saturated by SMX that dimensionless is expressed as $\theta_{s t}=t / t_{s t} ; x=C_{i} / C_{0} ; \mathrm{N}_{\mathrm{Di}}$ is the number of intraparticle mass transfer units $\left(N_{D i}=\tau D_{p} / R_{0}^{2}\right)$, with $\tau=L / u_{i}$, the space time. $P e$ is the Peclet number, $P e=u_{i} L / D_{A X}$. The axial dispersion parameter $\left(D_{A X}\right)$ was not available for the laboratory column, so it was considered the sole parameter model fit. A FORTRAN subroutine, PDECOL (Madsen and Sincovec 1979), was used to solve the proposed differential equation system for the fixed bed model. calculated as a fitting parameter in the load and elution steps for chloride, sulfate, nitrate and SMX are shown in Table 4. The experimental and theoretical breakthrough curves 524 for the load and elution steps obtained in the first cycle are shown in Fig. 8 and Fig. 9, respectively. A good correlation can be observed between experimental results and the numerical solution of the fixed bed model for the elution step, thus showing the validity of the model. However, in the loading step, although the model shows roughly fitting with experimental data, it does not fit in the beginning of the operation because this model was 
529 developed with boundary conditions that part from zero as can be observed in the Eq.

530 (17). However, in the two loading cycles performed, concentrations of all compounds

531 were detected from the first minutes of operation at the outlet of the column. Therefore,

532 to be able to adjust better the experimental values, it would be necessary to modify the

533 boundary conditions in the model, considering as boundary conditions in the solution the

534 proportion between the concentration detected at the outlet at time 0 and the total solution 535 concentration.

536

537

\section{Table 4

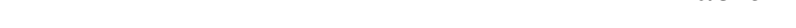

\section{Fig. 8}

538

\section{Fig. 9}

\section{Conclusions}

The removal of SMX in the presence of salts (sulfate, nitrate and chloride) using

a strong base anionic resin (Lewatit MP500) was carried out successfully. Batch experiments were conducted using synthetic solutions of SMX $\left(\mathrm{C}_{0}=62-124 \mathrm{mg} / \mathrm{L}\right)$ and a

544 fixed concentration of salts $\left(250 \mathrm{mg} \mathrm{Cl}^{-} / \mathrm{L}, 250 \mathrm{mg} \mathrm{SO}_{4}{ }^{2-} / \mathrm{L}^{2}\right.$ and $\left.50 \mathrm{mg} \mathrm{NO}_{3}{ }^{-} / \mathrm{L}\right)$ with an

$545 \mathrm{~L} / \mathrm{S}$ ratio (volume of liquid $(\mathrm{mL}) /$ mass of wet resin $(\mathrm{g}))=150-250$. Experiments with salts

546 in a single component system were also carried out in batch mode, using synthetic 547 solutions of nitrate $\left(\mathrm{C}_{0}=50-125 \mathrm{mg} / \mathrm{L}\right)$, sulfate $\left(\mathrm{C}_{0}=50-300 \mathrm{mg} / \mathrm{L}\right)$ and chloride $\left(\mathrm{C}_{0}=50\right.$ -

$548350 \mathrm{mg} / \mathrm{L}$ ) salts, respectively, with an $\mathrm{L} / \mathrm{S}$ ratio $=1000$, being the highest adsorption 549 capacity obtained for the sulfate. The adsorption process in mixtures was relatively fast, 
550

551

552

553

554

555

556

557

558

559

560

561

562

563

564

565

566

567

568

569

570

571

572

573

with equilibrium being established in 100 minutes. To study the equilibrium of the process, the experimental data were fitted to Langmuir isotherm for single systems and to the Extended Langmuir isotherm for the multicomponent system. The results showed that there was competition between components in the adsorption process in mixtures, decreasing the adsorption capacity of SMX because of the presence of co-existing anions, being sulfate who plays a more negative effect. The equilibrium constants for the Extended Langmuir isotherm were: $\mathrm{K}_{\mathrm{eq} \mathrm{SMX}}=1.4 \mathrm{~L} / \mathrm{g} \mathrm{SMX}, \mathrm{K}_{\mathrm{eq} \mathrm{N}}$ itrate $=6 \mathrm{~L} / \mathrm{g} \mathrm{NO}_{3}{ }^{-}$, and $\mathrm{K}_{\mathrm{eq} \text { Sulfate }}=9 \mathrm{~L} / \mathrm{g} \mathrm{SO}_{4}{ }^{2-}$, with a maximum adsorption capacity for $\mathrm{SMX} /$ salts system, $\mathrm{q}_{\mathrm{T}}=$ $105 \mathrm{~g} / \mathrm{L}$ wet resin. In the case of salts in a single component system, the results were: $\mathrm{K}_{\text {eq-Lang. Sulfate }}=151.6 \mathrm{~L} / \mathrm{g} \mathrm{SO}_{4}{ }^{2}$, q $\mathrm{q}_{\text {T Sulfate }}=76.9 \mathrm{~g} \mathrm{SO}_{4}{ }^{2-} / \mathrm{L}$ wet resin; $\mathrm{K}_{\text {eq-Lang Nitrate }}=66.7 \mathrm{~L} / \mathrm{g}$ $\mathrm{NO}_{3}{ }^{-}, \mathrm{q}_{\mathrm{T} \text { Nitrate }}=73.8 \mathrm{~g} \mathrm{NO}_{3}{ }^{-} / \mathrm{L}$ wet resin and $\mathrm{K}_{\text {eq-Lang. } \text { Chloride }}=12.7 \mathrm{~L} / \mathrm{g} \mathrm{Cl}^{-}, \mathrm{q}_{\mathrm{T}}$ Chloride $=35.2$ $\mathrm{g} \mathrm{Cl}^{-} / \mathrm{L}$ wet resin. Hence, the resin presents more affinity for the sulfate than for the other salts. The kinetics of adsorption of SMX in mixtures was studied using the pore diffusion model, obtaining intraparticle diffusivity value of $\mathrm{D}_{\mathrm{p} S M X}=1.3 \cdot 10^{-8} \mathrm{~cm}^{2} / \mathrm{s}$. In the case of salts in a single system the pore diffusivity values were also obtained.

Load and elution cycles in a fixed bed column were carried out with synthetic solution mixtures of SMX and salts, using Lewatit MP500 resin and a solution of $\mathrm{NaOH}$ $0.5 \mathrm{M}$ as the eluent. The retention capacity of the resin and the ability of the eluent were evaluated. The breakthrough curves showed that the resin was able to adsorb SMX despite the presence of salts. Furthermore, $\mathrm{NaOH}$ was found to be a good eluent because it allows the concentrating of sulfate and nitrate salts, thereby enabling simple treatment of these compounds, at the same time as recovering nearly $100 \%$ of SMX, sulfate and nitrate in all the elution steps. Fixed bed operation was simulated using a proposed model that takes into account axial dispersion, equilibrium and kinetic parameters for the system under 
574

575

576

577

study. The numerical solution shows a good agreement between experimental data and the predicted values for the elution curves.

\section{Acknowledgements}

Author Ana María López Fernández acknowledges a PhD fellowship from the Severo Ochoa Programme (Gobierno del Principado de Asturias, Spain).

\section{References}

Adams, C., ASCE, M., Wang, Y., Loftin, K., Meyer, M. (2002). "Removal of antibiotics from surface and distilled water in conventional water treatment processes.” J. Environ. Eng., 128, 253-260.

Ahmed, M.B., Zhou, J.L., Ngo, H.H., Guo, W. (2015). “Adsorptive removal of antibiotics from water and wastewater: Progress and challenges." Sci. Total Environ., 532, 112-126

Andreozzi, R., Canterino, M., Marotta, R., Paxeus, N. (2005). "Antibiotic removal from wastewaters: the ozonation of amoxicillin.” J. Hazard. Mater., 122, 243250.

Arevalo E, Rendueles M, Fernandez A, Rodrigues A, Diaz M., (1998) "Uptake of copper and cobalt in a complexing resin: shrinking-core model with two reaction fronts" Sep. Purif. Technol 13 (1), 37-46

Balcioğlu, L.A., Ötker, M. (2003). "Treatment of pharmaceutical wastewater containing antibiotics by $\mathrm{O}_{3} / \mathrm{H}_{2} \mathrm{O}_{2}$ processes." Chemosphere, 50, 85-95. 
Cho, H.H., Huang, H., Schwab, K. (2011). "Effects of solution chemistry on the adsorption of ibuprofen and triclosan onto carbon nanotubes." Langmuir, 27(21), $12960-12967$.

Choi, K.-J., Son, H.-J., Kim, S.-H. (2007). "Ionic treatment for removal of sulphonamide and tetracycline classes of antibiotic." Sci. Total Environ., 387, $247-256$.

Chong, K.H., Volesky, B. (1996). "Metal Biosorption Equilibria in a Ternary System.” Biotechnol. Bioeng., 49, 629-638.

Costa, C. Rodrigues, A. (1985a). "Design of cyclic fixed-bed adsorption processes. Part I: Phenol adsorption on polymeric adsorbents.” AIChE J., 31(10), 1645-1654. Costa, C., Rodrigues, A. (1985b). "Intraparticle diffusion of phenol in macroreticular adsorbents: modeling and experimental study of batch and CSTR adsorbents." Chem. Eng. Sci., 40(6), 983-993.

Crisafully, R., Milhome, M.A.L., Cavalcante, R.M., Silveira, E.R., De Keukeleire, D., Nascimiento, R.F. (2008). "Removal of some polycyclic aromatic hydrocarbons from petrochemical wastewater using low-cost adsorbent of natural origin." Bioresour. Technol., 99, 4515-4519.

Díaz-Cruz, M. Silvia, López de Alda, M.J., Barceló, D. (2003). "Environmental behavior and analysis of veterinary and human drugs in soils, sediments and sludge." Trends Anal. Chem., 22 (6), 340-351.

Fernández, A., Díaz, M.; Rodrigues, A.E., (1995). "Kinetic mechanisms in ion exchange processes" The Chem. Eng. J., 57, 17-25.

Fernández, A., Rendueles, M., Rodrigues, A., Díaz, M. (1994). "Co-ion behavior at high concentration cationic ion exchange.” Ind. Eng. Chem. Res., 33 (11), 27892794. 
Fernández, A.M.L, Rendueles, M., Díaz, M. (2013). “Sulfamethoxazole removal from synthetic solutions by ion exchange using a strong anionic resin in fixed bed." Solvent Extr. Ion Exch., 31, 763-781.

Grassi, M., Kaykioglu, G., Belgiorno, V., Lofrano, G. (2012). "Removal of Emerging Contaminants from Water and Wastewater by Adsorption Process.” in G. Lofrano (ed.), Emerging Compounds Removal from Wastewater: Natural and Solar Based Treatments, SpringBriefs in Green Chemistry for Sustainability, Chapter 2, pp.1537.

Gupta, V.K., Carrott, P.J.M., Ribeiro Carrott, M.M.L., Sushas, T.L. (2009). “Low cost adsorbents: growing approach to wastewater treatment- a review." Crit. Rev. Env. Sci. Technol., 39, 783-842.

Hari, A.C., Paruchuri, R.A., Sabatini, D.A. Kibbey, T.C.G. (2005). "Effects of pH and cationic and nonionic surfactants on the adsorption of pharmaceuticals to a natural aquifer material.” Environ. Sci. Technol., 39 (8), 2592-2598.

Helfferich, F. (1962). Ion Exchange, McGraw-Hill, New York.

Homen, V. and Santos, L. (2011). "Degradation and removal methods of antibiotics from aqueous matrices-A review." J. Environ. Manage., 92, 2304-2347.

Ji, L.L., Shao, Y., Xu, Z.Y., Zheng, S.R., Zhu, D.Q. (2010). “Adsorption of monoaromatic compounds and pharmaceuticals antibiotics on carbon nanotubes activated by KOH etching." Environ. Sci. Technol., 44, (16), 6429-6436.

Jiang, M., Yang, W., Zhang, Z., Yang, Z., Wang, Y. (2015). “Adsorption of three pharmaceuticals on two magnetic ion-exchange resins.” J. Environ. Sci., 31, 226234. 
Li, S.Z., Li, X.-Y., Wang, D.-Z. (2004). "Membrane (RO-UF) filtration for antibiotic wastewater treatment and recovery of antibiotics." Sep. Purif. Technol., 34 (1-3), 109-114.

López A.M.(2014). "Ion Exchange with commercial and synthesized resins for sulfamides and thiocyanate retention in individual and multicomponent systems" $\mathrm{PhD}$ Thesis. University of Oviedo. Spain

Madsen, N.K., Sincovec. R.F. (1979). "Algorithm 540: PDECOL, General Collocation Software for Partial Differential Equations [D3].” ACM Transactions on Mathematical Software (TOMS), 5 (3), 326-351.

Mehrjouei, M., Müller, S., Möller, D. (2014). “Energy consumption of three different advanced oxidation methods for water treatment: a cost effectiveness study." $J$. Clean Prod., 65, 178-183.

Pérez-Moya, M., Graells, M., Castells, G., Amigó, J., Ortega, E., Buhigas, G., Pérez, L.M., Mansilla, H.D. (2010). "Characterization of the degradation performance of the sulfamethazine antibiotic by Photo-Fenton process." Water Res., 44, 25332540 .

Putra, E.K., Pranowo, R., Sunarso, J., Indraswati, N., Ismadji. S. (2009). "Performance of activated carbon and bentonite for adsorption of amoxicillin from wastewater: mechanism, isotherms and kinetics." Water Res., 43, 2419-2430.

Rivera-Utrilla, J., Prados-Joya, G., Sánchez Polo, M., Ferro Garcia, M.A., BautistaToledo, I. (2009). "Removal of nitroimidazole antibiotics from aqueous solution by adsorption/bioadsorption on activated carbon.” J. Hazard. Mater., 170, 298305. 
Rodrigues, A.E., Tondeur, D. (1981). Percolation Processes: Theory and Applications, NATO ASI Series E33, Netherlands, Sijthoff \& Noordhoff Pub., pp. 31-81.

Shallcross, M., Herrmann, C.C., McCoy, B.J. (1988). “An improved model for the prediction of multicomponent ion exchange equilibria." Chem. Eng. Sci., 43, 279288.

Stackelberg, P.E., Gibs, J., Furlong, E.T., Meyer, M.T., Zaugg, S.D., Lippincott, R.L. (2007). "Efficiency of conventional drinking water treatment processes in removal of pharmaceuticals and other organic compounds." Sci. Total Environ., 377, 255272.

Stein, K., Ramil, M., Fink, G., Sander, M., Ternes, T.A. (2008). “Analysis and sorption of psychoactive drugs onto sediment." Environ. Sci. Technol., 42(17), $6415-6423$.

Sukul, P., Lamshöft, M., Zühlke, S., Spiteller, M., 2008. (2008). "Sorption and desorption of sulfadiazine in soil and soil-manure systems." Chemosphere, 73 (8), 1344-1350.

Tong, D.S., Zhou, C.H., Lu, Y., Yu, H., Zhang, G.F., Yu, W.H. (2010). “Adsorption of acid red dye on octadecyl trimetilammonium montmorillonite.” Appl. Clay Sci., $50,427-431$.

Trovó, A.G., Nogueira, R.F.P., Agüera, A., Sirtori, C., Fernández-Alba, A.R. (2009). "Photodegradation of sulfamethoxazole in various aqueous media: persistence, toxicity and photoproducts assessment." Chemosphere, 77, 1292-1298.

Vergili, I., Barlas, H. (2009). "Removal of selected pharmaceutical compounds from water by an organic polymer resin." Journal of Scientific \& Industrial Research, 68(5), 417-425. 

pharmaceuticals in river water and their elimination in a pilot-scale drinking water treatment plant." Environ. Sci. Technol., 41, 5077-5084.

695

Xu, W., Zhang, G., Zou, S.C., Li, X.D., Liu, Y.C. (2007). "Determination of selected antibiotics in the Victoria Harbour and the Pearl River, South China using highperformance liquid chromatography-electrospray ionization tandem mass spectrometry.” Environ. Pollut., 145, 672-679. 
Table 1 Characteristics of Lewatit MP500

General description

\begin{tabular}{ll}
\hline Ion form & $\mathrm{Cl}^{-}$ \\
Functional group & Quaternary amine (type I) \\
Polymer Structure & Macroporous \\
Bead side $>90 \%(\mathrm{~mm})$ & $0.47( \pm 0.06)$ \\
Density $(\mathrm{g} / \mathrm{mL})$ & 1.06 \\
Total capacity $(\min . \mathrm{eq} / \mathrm{L})$ & 1.1 \\
\hline
\end{tabular}


Table 2. Comparison of experimental data and calculated values from the extended Langmuir model for a multicomponent system containing SMX in different initial concentrations $\left(\mathrm{C}_{0}\right)$ and a fixed amount of salts $\left(50 \mathrm{mg} / \mathrm{L} \mathrm{NO}_{3}{ }^{-}, 250 \mathrm{mg} / \mathrm{L} \mathrm{SO}_{4}{ }^{{ }^{-}}\right.$and $\left.250 \mathrm{mg} / \mathrm{L} \mathrm{Cl}^{-}\right)$

\begin{tabular}{|c|c|c|c|c|c|c|c|c|c|c|c|}
\hline \multirow{3}{*}{$\mathrm{L} / \mathrm{S}$} & $\mathrm{C}_{0}$ & \multicolumn{4}{|c|}{$\mathrm{C}_{\mathrm{e}, \mathrm{i} \text {-experimental }}$} & \multicolumn{3}{|c|}{$\mathrm{q}_{\mathrm{e}, \mathrm{i} \text {-experimental }}$} & \multicolumn{3}{|c|}{$\mathrm{q}_{\mathrm{e}, \mathrm{i} \text {-calculated }}$} \\
\hline & $(\mathrm{g} / \mathrm{L})$ & \multicolumn{4}{|c|}{$(g / L)$} & \multicolumn{3}{|c|}{ (g/L resin) } & \multicolumn{3}{|c|}{ (g/L resin) } \\
\hline & SMX & SMX & $\mathrm{NO}_{3}^{-}$ & $\mathrm{SO}_{4}{ }^{2^{-}}$ & $\mathrm{Cl}^{-}$ & SMX & $\mathrm{NO}_{3}{ }^{-}$ & $\mathrm{SO}_{4}^{2^{-}}$ & SMX & $\mathrm{NO}_{3}^{-}$ & $\mathrm{SO}_{4}{ }^{-2}$ \\
\hline 150 & 0.062 & 0.034 & 0.012 & 0.05466 & 0.25 & 4.5 & 5.1 & 31 & 4.6 & 4.7 & 32.1 \\
\hline 200 & 0.092 & 0.0589 & 0.0166 & 0.07 & 0.25 & 7.2 & 7.1 & 34.9 & 7.6 & 5.8 & 36.5 \\
\hline 200 & 0.124 & 0.0844 & 0.0171 & 0.078 & 0.25 & 8.4 & 7.3 & 36.5 & 10.4 & 5.6 & 38.3 \\
\hline 250 & 0.124 & 0.0920 & 0.021 & 0.097 & 0.25 & 9.0 & 8.3 & 40.6 & 10.9 & 6.2 & 43.1 \\
\hline & & & & & & & & & SMX & $\mathrm{NO}_{3}^{-}$ & $\mathrm{SO}_{4}{ }^{2-}$ \\
\hline & & & & & & & & $R^{2}$ & 0.997 & 0.9912 & 0.999 \\
\hline
\end{tabular}


Table 3. Langmuir isotherm parameters obtained in $\mathrm{SMX}, \mathrm{NO}^{-}, \mathrm{SO}_{4}{ }^{2-}, \mathrm{Cl}^{-}$in single system

\begin{tabular}{ccccc}
\hline & $\mathrm{K}_{\mathrm{eq}}(\mathrm{L} / \mathrm{g})$ & $\mathrm{q}_{\mathrm{T}}(\mathrm{g} / \mathrm{L}$ resin $)$ & $\mathrm{R}^{2}$ & $\mathrm{E}_{\mathrm{i}}$ \\
\hline $\mathrm{SMX}$ & 15.8 & 258 & 0.9897 & 0.036 \\
$\mathrm{NO}^{-}$ & 66.7 & 73.8 & 0.9973 & 0.002 \\
$\mathrm{SO}_{4}{ }^{2-}$ & 151.6 & 76.9 & 0.9986 & 0.002 \\
$\mathrm{Cl}^{-}$ & 12.7 & 35.2 & 0.9925 & 0.008 \\
\hline$E_{i}=$ objective function (dimensionless) & &
\end{tabular}

$E_{i}=$ objective function (dimensionless) 
Table 4. Fixed bed operating parameters

\begin{tabular}{|c|c|c|c|c|}
\hline & $\mathrm{SO}_{4}^{2-}$ & $\mathrm{Cl}^{-}$ & $\mathrm{NO}_{3}^{-}$ & SMX \\
\hline Keq-CSF & 68.54 & 23.35 & 48.72 & 3.30 \\
\hline Diffusivity in pores $\left(\mathrm{cm}^{2} / \mathrm{s}\right)$ & $2.7 \cdot 10^{-8}$ & $3.9 \cdot 10^{-8}$ & $2.3 \cdot 10^{-8}$ & $1.3 \cdot 10^{-8}$ \\
\hline $\mathrm{D}_{\mathrm{AX}}\left(\mathrm{cm}^{2} / \mathrm{s}\right)$ load & 12 & 16 & 12 & 5 \\
\hline$D_{A X}\left(\mathrm{~cm}^{2} / \mathrm{s}\right)$ elution & 2 & 1 & 0.5 & 2 \\
\hline Retention Capacity (mg/mL resin) $1^{\text {st }}$ cycle & 50 & 42 & 15 & 5 \\
\hline Retention Capacity (mg/mL resin) $2^{\text {nd }}$ cycle & 57 & 49 & 7.2 & 4 \\
\hline Flow (mL/min) & \multicolumn{4}{|c|}{11} \\
\hline Bed Porosity $\left(\varepsilon_{1}\right)$ & \multicolumn{4}{|c|}{0.5} \\
\hline Particle Porosity & \multicolumn{4}{|c|}{0.34} \\
\hline Bed Height $(\mathrm{cm})$ & \multicolumn{4}{|c|}{3} \\
\hline
\end{tabular}




\section{FIGURE CAPTIONS}

Fig. 1. Comparison of experimental data with predicted values from the Langmuir isotherm for SMX in mixture with salts $\left(50 \mathrm{mg} / \mathrm{L} \mathrm{NO}_{3}{ }^{-}, 250 \mathrm{mg} / \mathrm{L} \mathrm{SO}_{4}{ }^{2-}, 250 \mathrm{mg} / \mathrm{L} \mathrm{Cl}^{-}\right)$considering no competition between species.

Fig.2 . Comparison of experimental data with predicted values from the Langmuir isotherm for nitrate, sulfate and chloride in a single component system.

Fig. 3. Comparison of experimental data with the values predicted by the Extended Langmuir isotherm for a multicomponent system. Initial concentrations: $62-124 \mathrm{mg} / \mathrm{L} \mathrm{SMX,} 50 \mathrm{mg} / \mathrm{L}$ $\mathrm{NO}_{3}^{-}, 250 \mathrm{mg} / \mathrm{L} \mathrm{SO}_{4}{ }^{2^{-}}, 250 \mathrm{mg} / \mathrm{L} \mathrm{Cl}^{-}$.

Fig. 4- Fitting of kinetics data using the pore diffusion model for the adsorption of a synthetic solution of SMX at different concentrations (62-124 mg SMX/L) and concentrations of salts $\left(250 \mathrm{mg} / \mathrm{L} \mathrm{SO}_{4}{ }^{2-}, 250 \mathrm{mg} / \mathrm{L} \mathrm{Cl}^{-}, 50 \mathrm{mg} / \mathrm{L} \mathrm{NO}_{3}{ }^{-}\right)$onto Lewatit MP500 resin.

Fig 5. Fitting of kinetics data using the pore diffusion model for the adsorption of nitrate (a), sulfate (b) and chloride (c) in synthetic solutions at different concentrations.

Fig. 6. Breakthrough curves for the adsorption of SMX, chloride, sulfate and nitrate from synthetic solutions prepared in distilled water (a), and elution using $\mathrm{NaOH} 0.5 \mathrm{M}$ (b) onto Lewatit MP500. Conditions: $[\mathrm{SMX}]_{0}=125 \mathrm{mg} / \mathrm{L},\left[\mathrm{SO}_{4}{ }^{2-}\right]_{0}=250 \mathrm{mg} / \mathrm{L},\left[\mathrm{Cl}^{-}\right]=250 \mathrm{mg} / \mathrm{L}$, $\left[\mathrm{NO}_{3}{ }^{-}\right]_{0}=50 \mathrm{mg} / \mathrm{L}$; flow rate load $=11 \mathrm{ml} / \mathrm{min}$, flow rate elution $=10 \mathrm{~mL} / \mathrm{min}$, volume resin $=1.9$ $\mathrm{mL}(\mathrm{Z}=3 \mathrm{~cm})$.

Fig.7. Breakthrough curves for the adsorption (a) of SMX, chloride, sulfate and nitrate from synthetic solutions prepared in distilled water, and elution (b) using $\mathrm{NaOH} 0.5 \mathrm{M}$, onto Lewatit MP500. Conditions: $[\mathrm{SMX}]_{0}=90 \mathrm{mg} / \mathrm{L},\left[\mathrm{SO}_{4}{ }^{2-}\right]_{0}=250 \mathrm{mg} / \mathrm{L},\left[\mathrm{Cl}^{-}\right]=250 \mathrm{mg} / \mathrm{L},\left[\mathrm{NO}_{3}{ }^{-}\right]_{0}=50$ $\mathrm{mg} / \mathrm{L}$; flow rate load= $10.5 \mathrm{ml} / \mathrm{min}$, flow rate elution $=9 \mathrm{~mL} / \mathrm{min}$, volume resin= $1.9 \mathrm{~mL} ; \mathrm{Z}=3$ $\mathrm{cm}$.

Fig. 8. Experimental and theoretical load breakthrough curves for SMX, sulfate, nitrate and chloride from synthetic solutions prepared in distilled water, onto Lewatit MP500. Conditions: $[\mathrm{SMX}]_{0}=125 \mathrm{mg} / \mathrm{L},\left[\mathrm{SO}_{4}{ }^{2-}\right]_{0}=250 \mathrm{mg} / \mathrm{L},\left[\mathrm{Cl}^{-}\right]=250 \mathrm{mg} / \mathrm{L},\left[\mathrm{NO}_{3}{ }^{-}\right]_{0}=50 \mathrm{mg} / \mathrm{L}$; flow rate $=11$ $\mathrm{ml} / \mathrm{min}$; volume resin= $1.9 \mathrm{~mL}(\mathrm{Z}=3 \mathrm{~cm})$. 
Fig. 9. Experimental and theoretical elution curves for SMX (a), sulfate (b), nitrate(c) and chloride (d) from synthetic solutions using $\mathrm{NaOH} 0.5 \mathrm{M}$ as eluent in a fixed bed onto Lewatit MP500. Conditions: $[\mathrm{SMX}]_{0}=125 \mathrm{mg} / \mathrm{L},\left[\mathrm{SO}_{4}{ }^{2-}\right]_{0}=250 \mathrm{mg} / \mathrm{L},\left[\mathrm{Cl}^{-}\right]=250 \mathrm{mg} / \mathrm{L},\left[\mathrm{NO}_{3}{ }^{-}\right]_{0}=50$ $\mathrm{mg} / \mathrm{L}$; flow rate $=10 \mathrm{ml} / \mathrm{min}$, volume resin= $1.9 \mathrm{~mL}(\mathrm{Z}=3 \mathrm{~cm})$. 


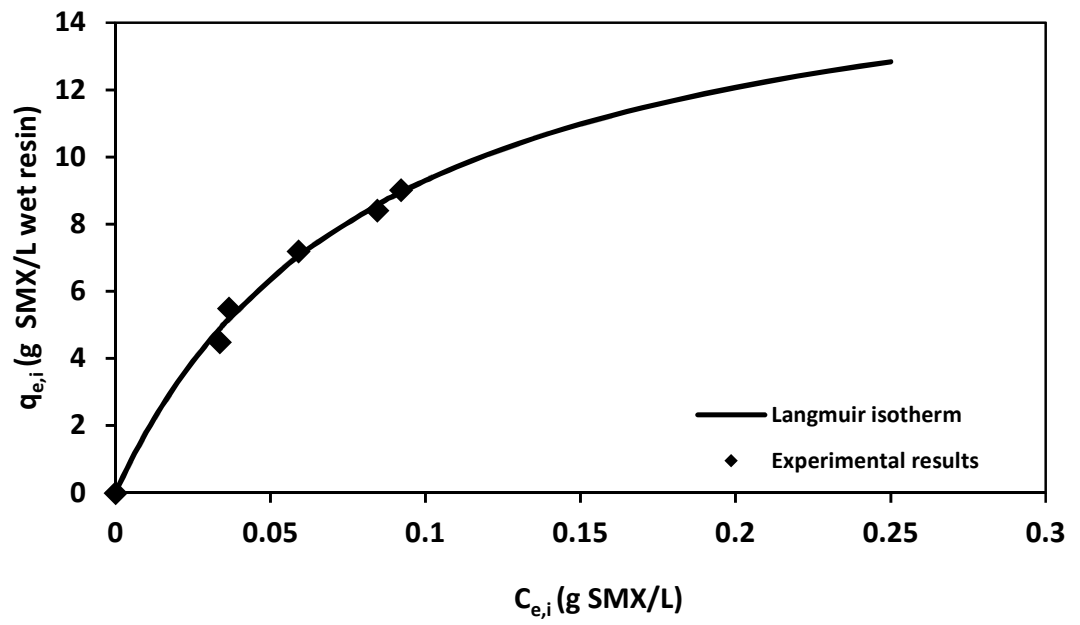




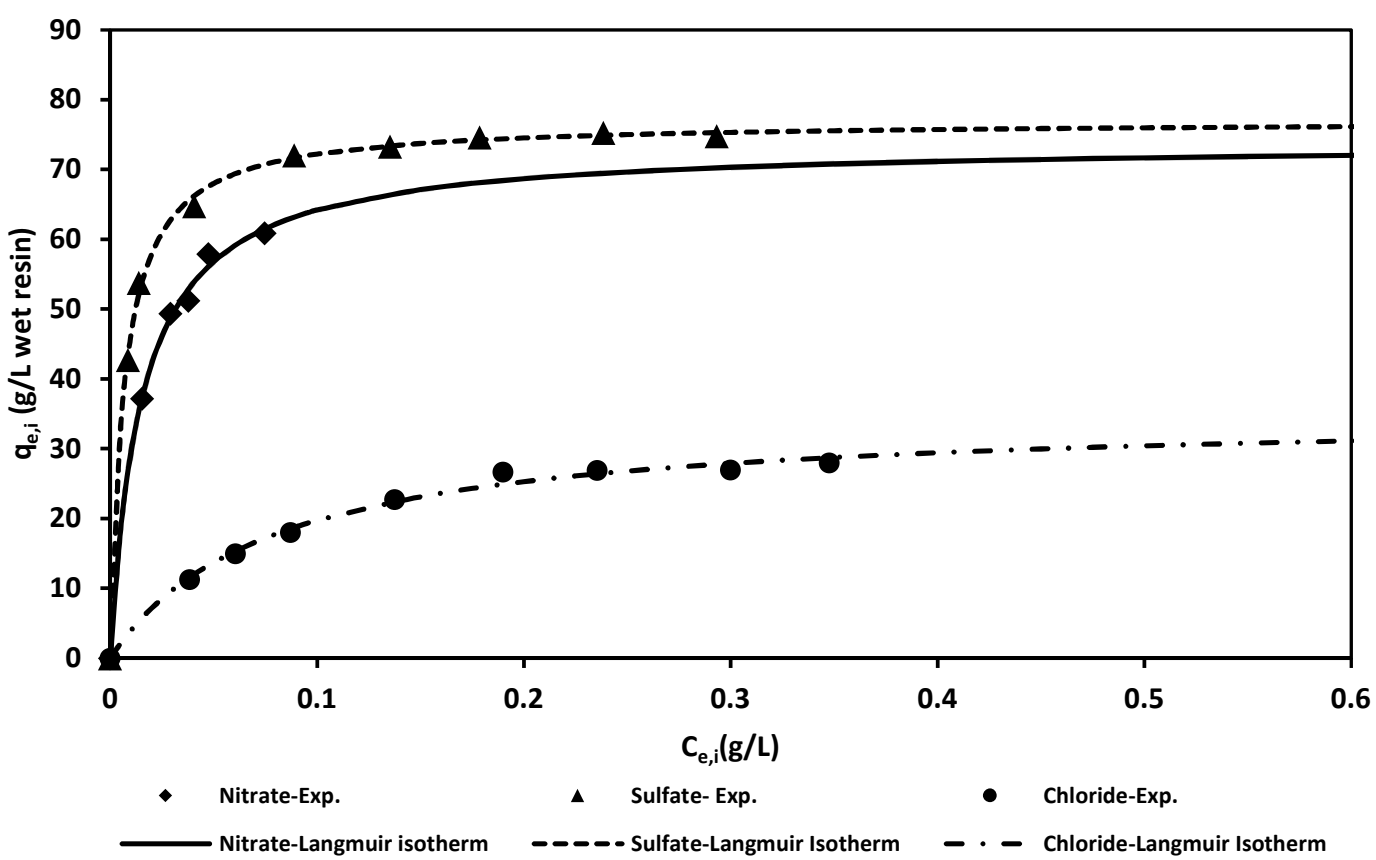




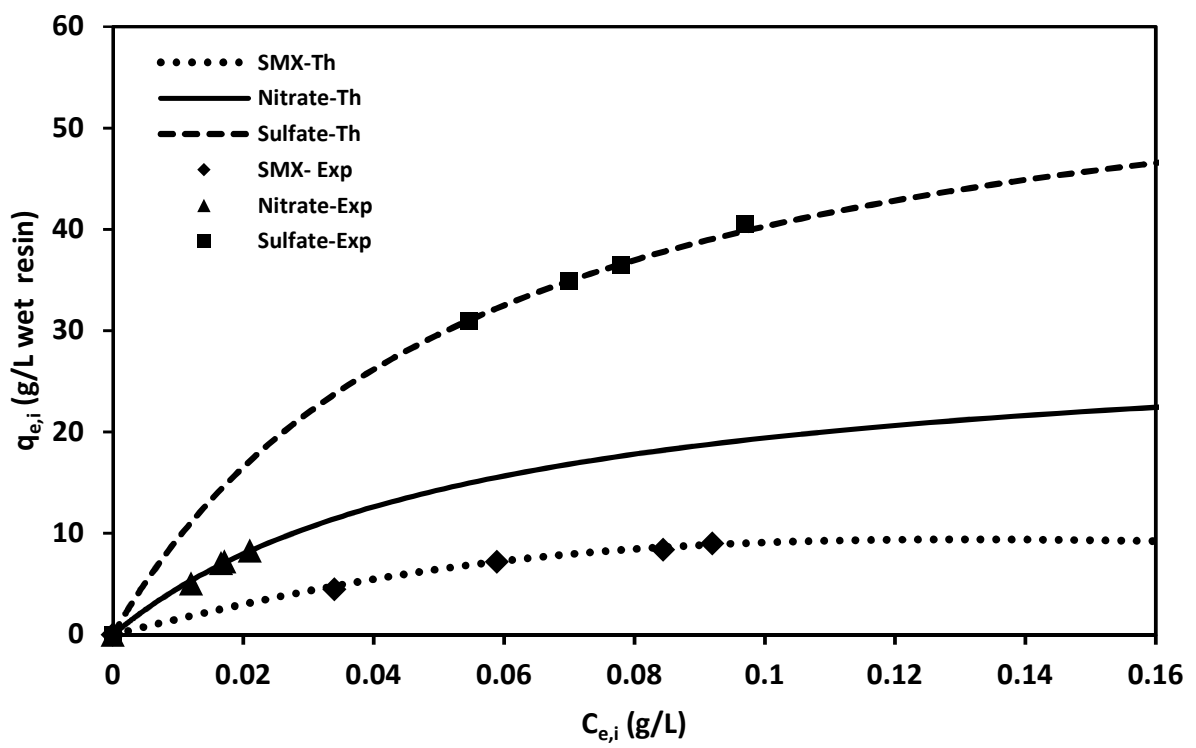




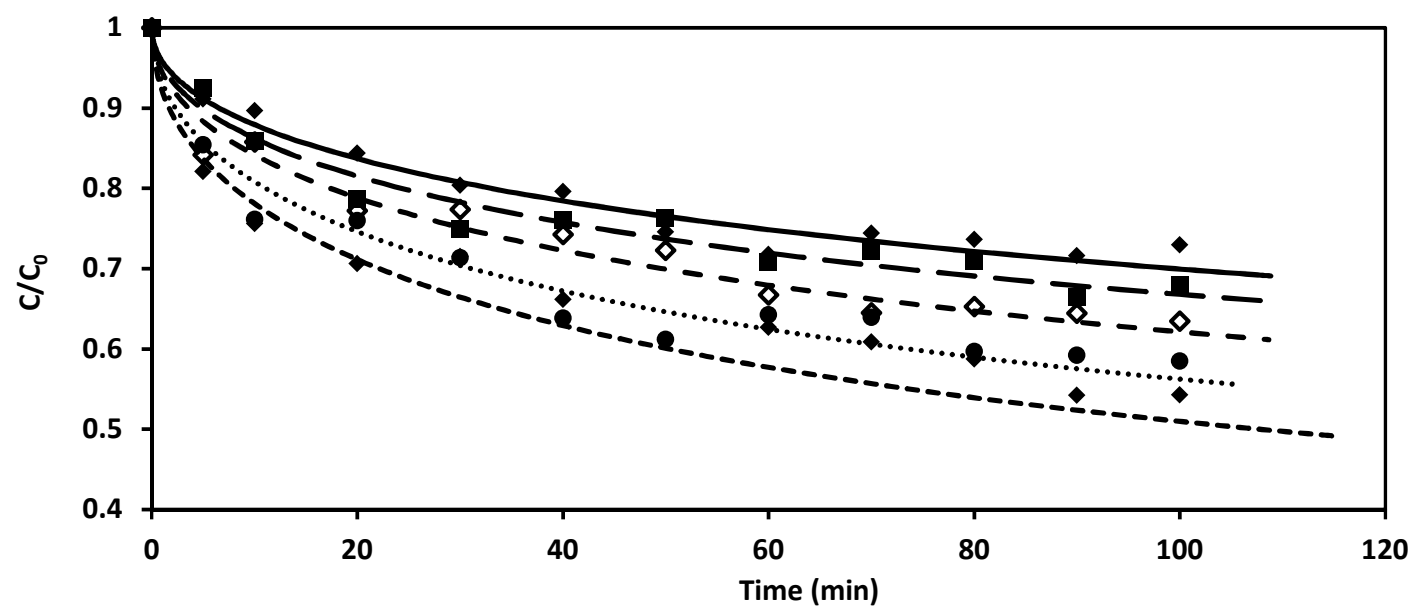

Th. $[\mathrm{SMX}]=124 \mathrm{mg} / \mathrm{L} ; \mathrm{L} / \mathrm{S}=250$

- Exp. $[S M X]=62 \mathrm{mg} / \mathrm{L} ; \mathrm{L} / \mathrm{S}=200$

- Exp. $[S M X]=124 \mathrm{mg} / \mathrm{L} ; \mathrm{L} / \mathrm{S}=200$
- - Th. [SMX] $62 \mathrm{mg} / \mathrm{L} ; \mathrm{L} / \mathrm{S}=150$

- $\operatorname{Exp}[S M X]=124 \mathrm{mg} / \mathrm{L} ; \mathrm{L} / \mathrm{S}=250$
- Exp. $[S M X]=92 \mathrm{mg} / \mathrm{L} ; \mathrm{L} / \mathrm{S}=\mathbf{2 0 0}$
Th. $[S M X]=124 \mathrm{mg} / \mathrm{L} ; \mathrm{L} / \mathrm{S}=200$

- Exp. $[S M X]=62 \mathrm{mg} / \mathrm{L} ; \mathrm{L} / \mathrm{S}=150$ 

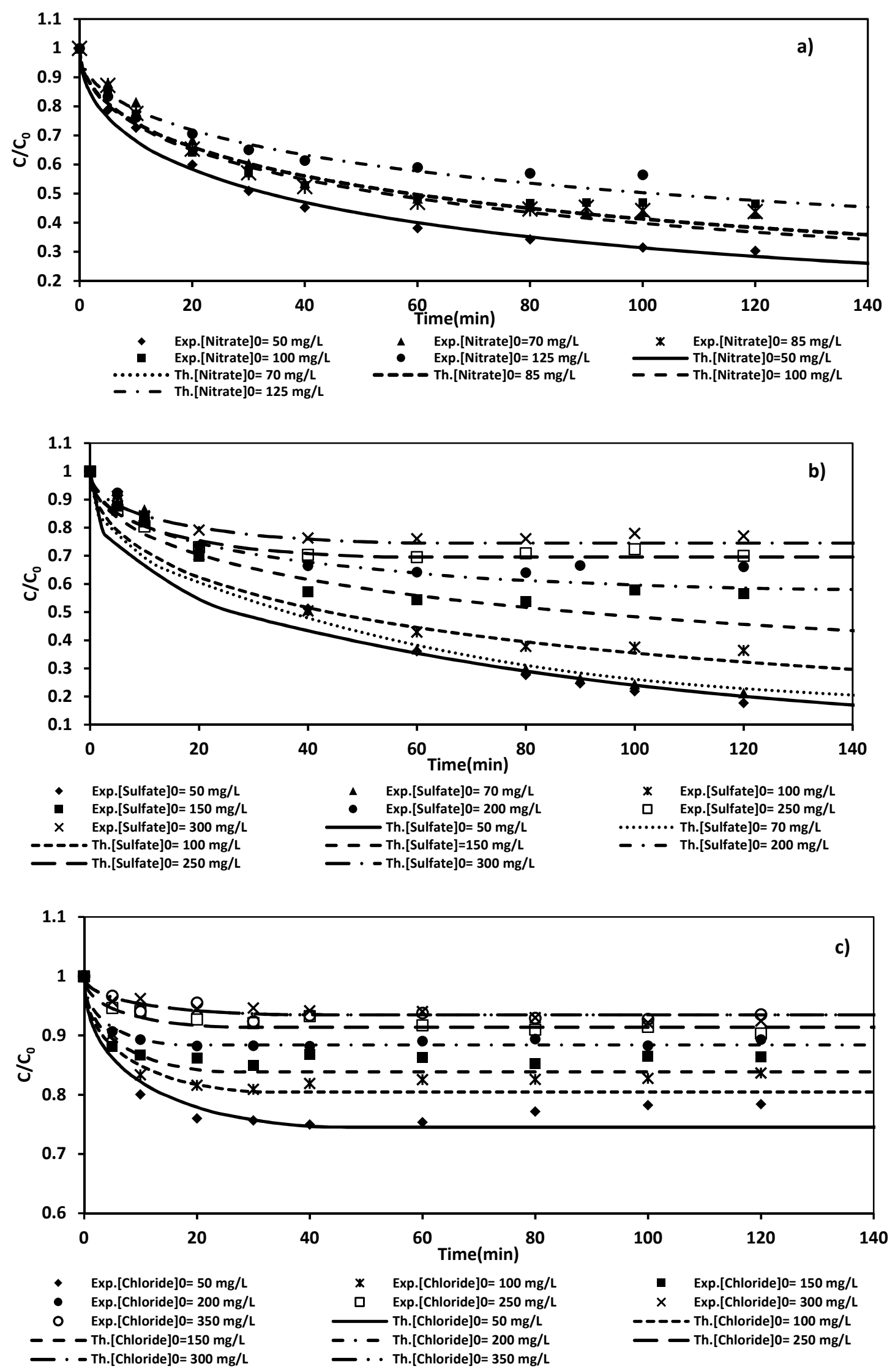

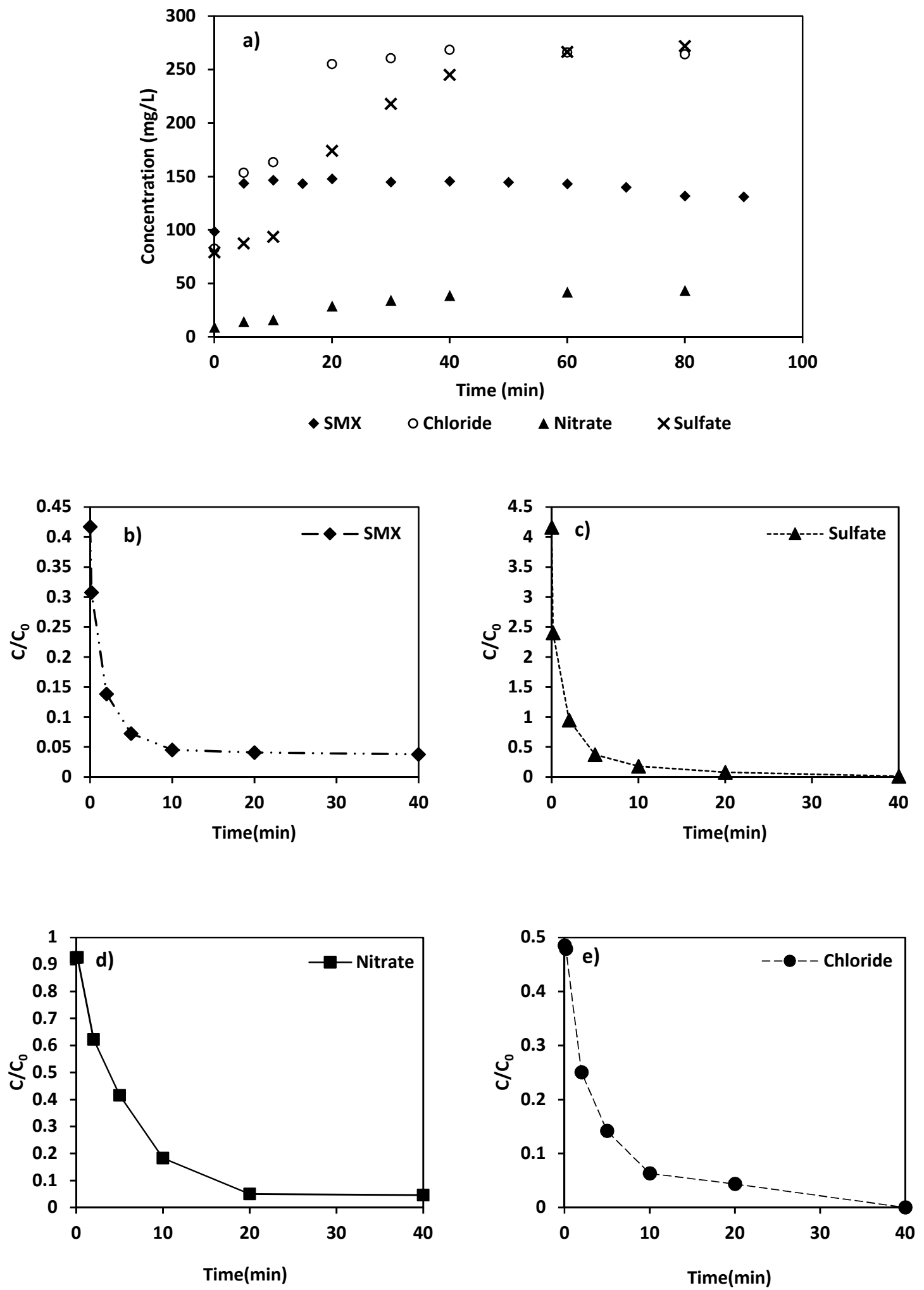

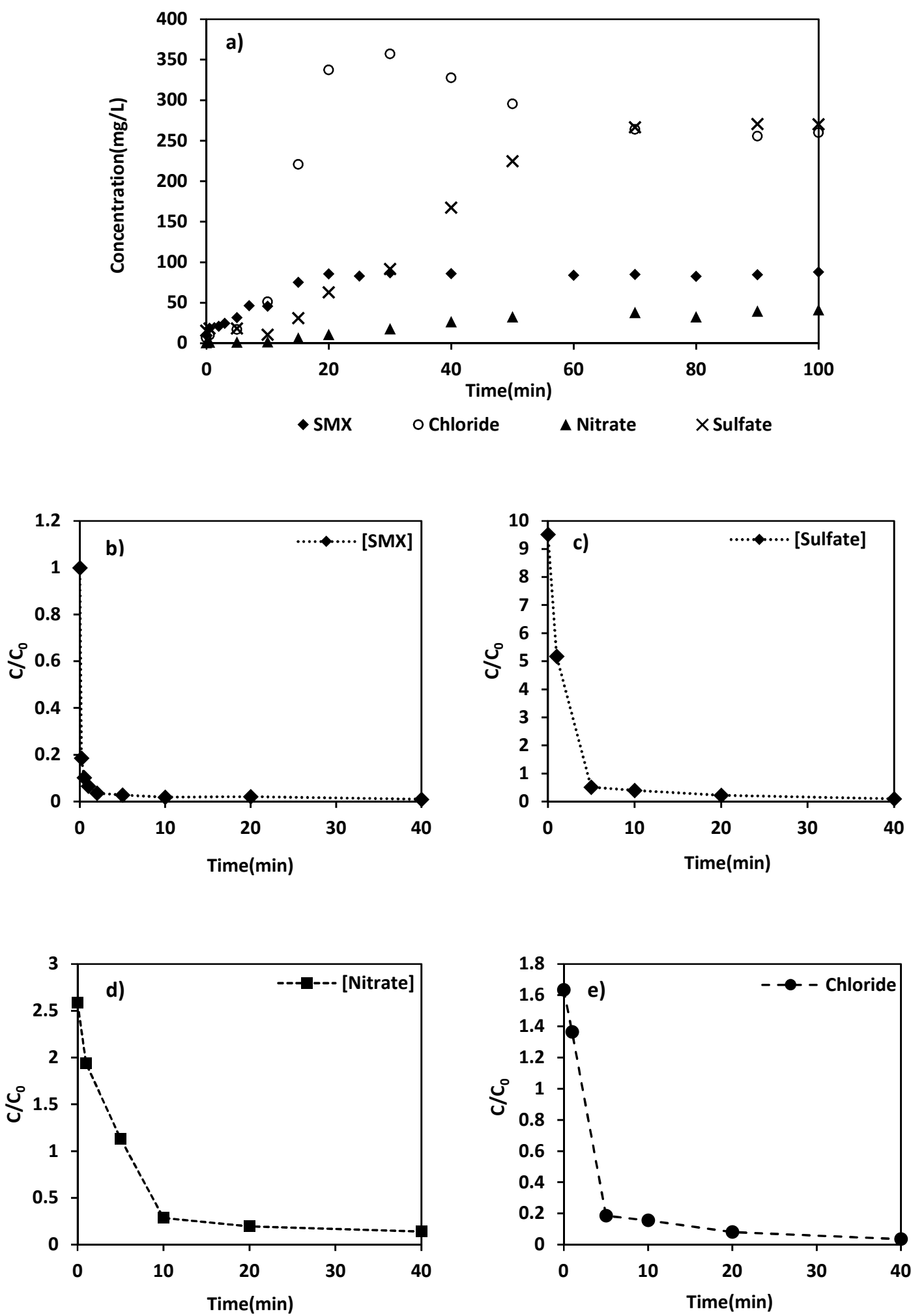


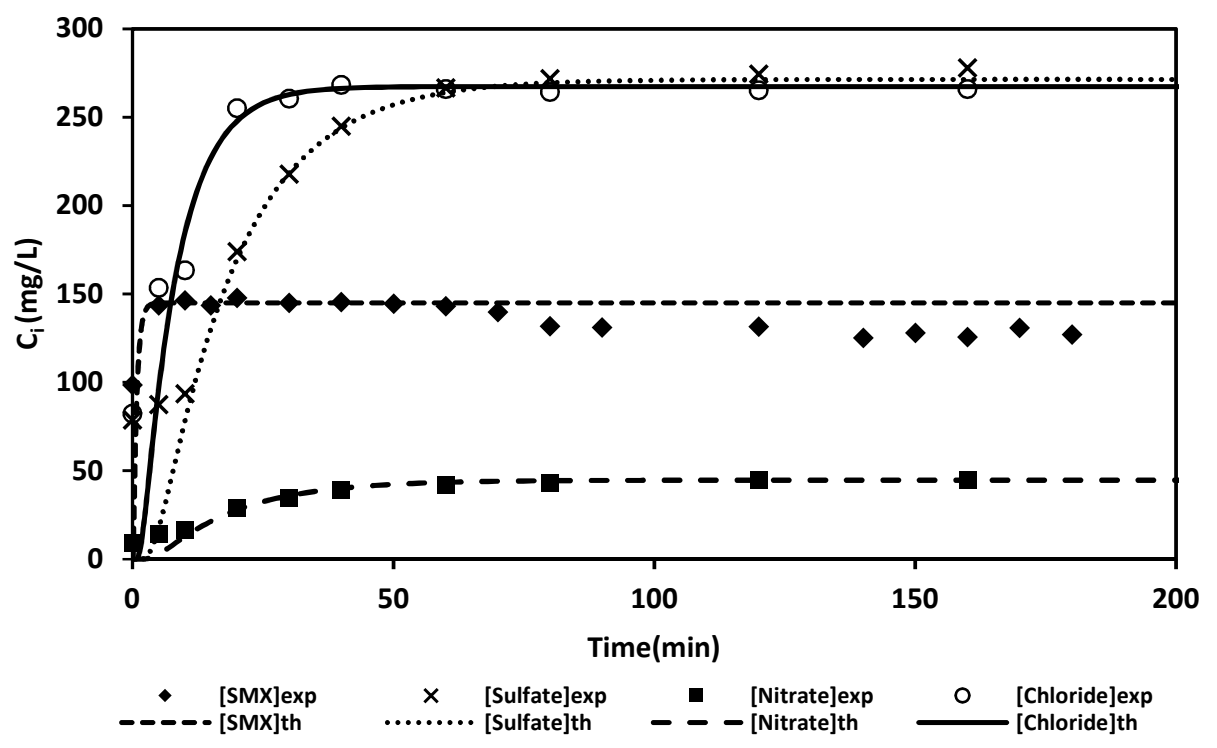



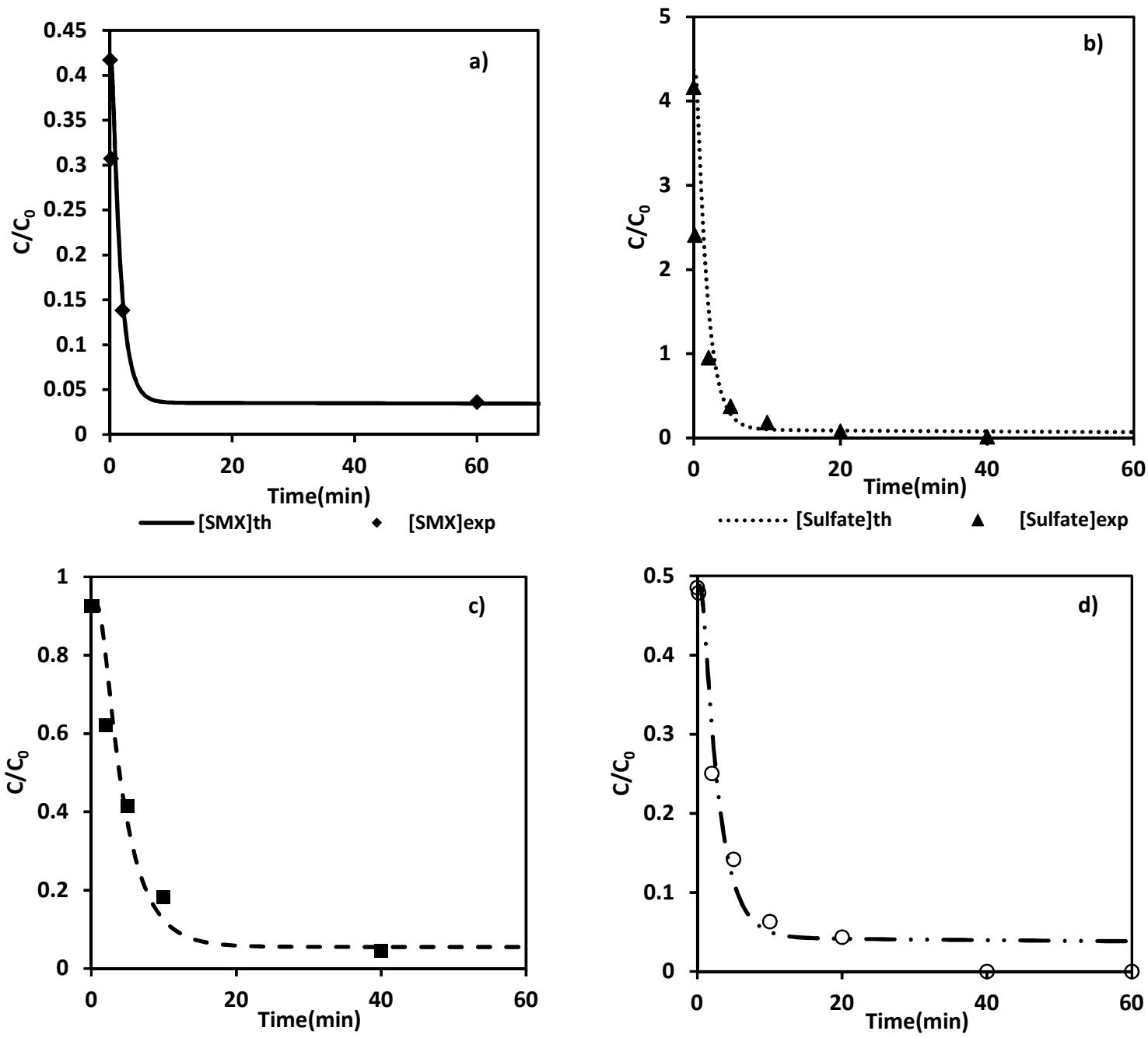

$-0-[$ Nitrate]th

- [Nitrate]exp

—.. [Chloride]th $\circ$ [Chloride]exp 


\title{
ASCE Authorship, Originality, and Copyright Transfer Agreement
}

\author{
Publication Title: journal of environmental engineering \\ Manuscript Title: COMPETITION OF SALTS WITH SULFAMETHOXAZOLE IN AN ANIONIC ION EXCHANGE PROCESS
}

Author(s) - Names, postal addresses, and e-mail addresses of all authors

Ana Maria López Fernández, Department of Chemical Engineering and Environmental Technology, University of Oviedo, Faculty of Chemistry, C/ Julián Claveria s/n, 33071 Oviedo, Spain. E.mail: ana_If_84@ @hotmail.com

Manuel Rendueles Department of Chemical Engineering and Environmental Technology, University of Oviedo, Faculty of Chemistry, C/ Juliản Claveria s/n, 33071 Oviedo, Spain. E.mail: mrenduel@uniovi.es

Mario Dlaz Department of Chemical Engineering and Environmental Technology, University of Oviedo, Faculty of Chemistry, C/ Julian Claveria s/n, 33071 Oviedo, Spain. E.mail: mariodiaz@uniovi.es

\section{Authorship Responsibility}

To protect the integrity of authorship, only people who have significantly contributed to the research or project and manuscript preparation shall be listed as coauthors. The corresponding author attests to the fact that anyone named as a coauthor has seen the final version of the manuscript and has agreed to its submission for publication. Deceased persons who meet the criteria for coauthorship shall be included, with a footnote reporting date of death. No fictitious name shall be given as an author or coauthor. An author who submits a manuscript for publication accepts responsibility for having properly included all, and only, qualified coauthors.

I, the corresponding author, confirm that the authors listed on the manuscript are aware of their authorship status and qualify to be authors on the manuscript according to the guidelines above.

Manuel Rendueles Mag, Sis 2017

\section{Originality of Content}

ASCE respects the copyright ownership of other publishers. ASCE requires authors to obtain permission from the copyright holder to reproduce any material that (1) they did not create themselves and/or (2) has been previously published, to include the authors' own work for which copyright was transferred to an entity other than ASCE. Each author has a responsibility to identify materials that require permission by including a citation in the figure or table caption or in extracted text. Materials re-used from an open access repository or in the public domain must still include a citation and URL, if applicable. At the time of submission, authors must provide verification that the copyright owner will permit re-use by a commercial publisher in print and electronic forms with worldwide distribution. For Conference Proceeding manuscripts submitted through the ASCE online submission system, authors are asked to verify that they have permission to re-use content where applicable. Written permissions are not required at submission but must be provided to ASCE if requested. Regardless of acceptance, no manuscript or part of a manuscript will be published by ASCE without proper verification of all necessary permissions to re-use. ASCE accepts no responsibility for verifying permissions provided by the author. Any breach of copyright will result in retraction of the published manuscript.

I, the corresponding author, confirm that all of the content, figures (drawings, charts, photographs, etc.), and tables in the submitted work are either original work created by the authors listed on the manuscript or work for which permission to reuse has been obtained from the creator. For any figures, tables, or text blocks exceeding 100 words from a journal article or 500 words from a book, written permission from the copyright holder has been obtained and supplied with the submission.

\section{Manuel Rendueles}

Print name

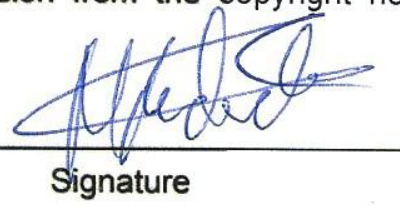

\section{Copyright Transfer}

ASCE requires that authors or their agents assign copyright to ASCE for all original content published by ASCE. The author(s) warrant(s) that the above-cited manuscript is the original work of the author(s) and has never been published in its present form. 
The undersigned, with the consent of all authors, hereby transfers, to the extent that there is copyright to be transferred, the exclusive copyright interest in the above-cited manuscript (subsequently called the "work") in this and all subsequent editions of the work (to include closures and errata), and in derivatives, translations, or ancillaries, in English and in foreign translations, in all formats and media of expression now known or later developed, including electronic, to the American Society of Civil Engineers subject to the following:

- The undersigned author and all coauthors retain the right to revise, adapt, prepare derivative works, present orally, or distribute the work, provided that all such use is for the personal noncommercial benefit of the author(s) and is consistent with any prior contractual agreement between the undersigned and/or coauthors and their employer(s).

- No proprietary right other than copyright is claimed by ASCE.

- If the manuscript is not accepted for publication by ASCE or is withdrawn by the author prior to publication (online or in print), this transfer will be null and void.

- Authors may post a PDF of the ASCE-published version of their work on their employers' Intranet with password protection. The following statement must appear with the work: "This material may be downloaded for personal use only. Any other use requires prior permission of the American Society of Civil Engineers."

- Authors may post the final draft of their work on open, unrestricted Internet sites or deposit it in an institutional repository when the draft contains a link to the published version at www.ascelibrary.org. "Final draft" means the version submitted to ASCE after peer review and prior to copyediting or other ASCE production activities; it does not include the copyedited version, the page proof, a PDF, or full-text HTML of the published version.

Exceptions to the Copyright Transfer policy exist in the following circumstances. Check the appropriate box below to indicate whether you are claiming an exception:

U.S. GOVERNMENT EMPLOYEES: Work prepared by U.S. Government employees in their official capacities is not subject to copyright in the United States. Such authors must place their work in the public domain, meaning that it can be freely copied, republished, or redistributed. In order for the work to be placed in the public domain, ALL AUTHORS must be official U.S. Government employees. If at least one author is not a U.S. Government employee, copyright must be transferred to ASCE by that author.

CROWN GOVERNMENT COPYRIGHT: Whereby a work is prepared by officers of the Crown Government in their official capacities, the Crown Government reserves its own copyright under national law. If ALL AUTHORS on the manuscript are Crown Government employees, copyright cannot be transferred to ASCE; however, ASCE is given the following nonexclusive rights: (1) to use, print, and/or publish in any language and any format, print and electronic, the above-mentioned work or any part thereof, provided that the name of the author and the Crown Government affiliation is clearly indicated; (2) to grant the same rights to others to print or publish the work; and (3) to collect royalty fees. ALL AUTHORS must be official Crown Government employees in order to claim this exemption in its entirety. If at least one author is not a Crown Government employee, copyright must be transferred to ASCE by that author.

WORK-FOR-HIRE: Privately employed authors who have prepared works in their official capacity as employees must also transfer copyright to ASCE; however, their employer retains the rights to revise, adapt, prepare derivative works, publish, reprint, reproduce, and distribute the work provided that such use is for the promotion of its business enterprise and does not imply the endorsement of ASCE. In this instance, an authorized agent from the authors' employer must sign the form below.

U.S. GOVERNMENT CONTRACTORS: Work prepared by authors under a contract for the U.S. Government (e.g., U.S. Government labs) may or may not be subject to copyright transfer. Authors must refer to their contractor agreement. For works that qualify as U.S. Government works by a contractor, ASCE acknowledges that the U.S. Government retains a nonexclusive, paid-up, irrevocable, worldwide license to publish or reproduce this work for U.S. Government purposes only. This policy DOES NOT apply to work created with U.S. Government grants.

I, the corresponding author, acting with consent of all authors listed on the manuscript, hereby transfer copyright or claim exemption to transfer copyright of the work as indicated above to the American Society of Civil Engineers.

\section{Manuel Rendueles}

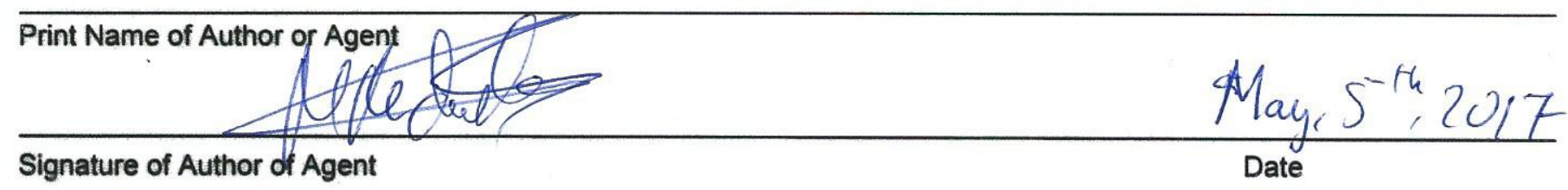

More information regarding the policies of ASCE can be found at http://www.asce.org/authorsandeditors 


\section{$\underline{\text { Editorial comments }}$}

Dear LaTarsha

We have introduced the corrections you have indicated us. The spelling of HPCL was a mistake, it is HPLC. The all three has been introduced in the text.

References of Costa $1985 \mathrm{a}$ and $\mathrm{b}$ have been indicated in the text and in the references list. 
Click here to access/download Track Changes Version Manuscript16[288] - corrected-Track Changes.docx 